ANDRÉ DOMINGUES DA SILVA JALBUT

\title{
AVALIAÇÃO DO IMPACTO DA CONFIANÇA EM CADEIAS DE SUPRIMENTOS ATRAVÉS DE SIMULAÇÃO BASEADA EM AGENTES
}




\section{ANDRÉ DOMINGUES DA SILVA JALBUT}

\section{AVALIAÇÃO DO IMPACTO DA CONFIANÇA EM CADEIAS DE SUPRIMENTOS ATRAVÉS DE SIMULAÇÃO BASEADA EM AGENTES}

Dissertação apresentada à Escola Politécnica da Universidade de São Paulo para obtenção do título de Mestre em Ciências

Área de Concentração: Engenharia de Computação

Orientador: Prof. Dr. Jaime Simão Sichman 
Autorizo a reprodução e divulgação total ou parcial deste trabalho, por qualquer meio convencional ou eletrônico, para fins de estudo e pesquisa, desde que citada a fonte.

Este exemplar foi revisado e corrigido em relação à versão original, sob responsabilidade única do autor e com a anuência de seu orientador.

São Paulo, de de

Assinatura do autor:

Assinatura do orientador:

\section{Catalogação-na-publicação}

Jalbut, André Domingues da Silva

AVALIAÇÃO DO IMPACTO DA CONFIANÇA EM CADEIAS DE

SUPRIMENTOS ATRAVÉS DE SIMULAÇÃO BASEADA EM AGENTES / A. D.

S. Jalbut -- versão corr. -- São Paulo, 2018.

$65 \mathrm{p}$.

Dissertação (Mestrado) - Escola Politécnica da Universidade de São Paulo. Departamento de Engenharia de Computação e Sistemas Digitais.

1.Simulação baseada em multi-agentes 2.Cadeias de suprimentos 3.Confiança e reputação 4.Beer Game I.Universidade de São Paulo. Escola Politécnica. Departamento de Engenharia de Computação e Sistemas Digitais II.t. 
"A melhor maneira de saber se você pode confiar em alguém é confiar"

Ernest Hemingway

"Os sentidos enganam de tempos em tempos, e é prudente nunca confiar plenamente naqueles que já nos enganaram uma vez."

Rene Descartes

"Quando consumidores compram um Toyota, eles não estão apenas comprando um carro, um caminhão, uma van. Eles estão depositando sua confiança em nossa companhia." 


\section{AGRADECIMENTOS}

Agradeço ao meu orientador Prof. Dr. Jaime Sichman pela disponibilidade, afinco e primor dedicados à elaboração deste trabalho, assim como pelos conhecimentos transmitidos a mim ao longo do processo.

Agradeço também a todos os colegas e professores do LTI, que me auxiliaram em uma série de questões práticas e com quem vivenciei experiências enriquecedoras no laboratório, em sala de aula e eventos acadêmicos.

Agradeço ainda aos meus queridos familiares, entre eles minha mãe Elisabeth, meu pai Pedro e minha irmã Beatriz, por todo o amparo e incentivo necessários para cumprir mais uma missão de vida.

Agradeço, por fim, à minha amada Beatriz, pela honra e felicidade de caminhar ao meu lado durante todos esses anos de foco e dedicação a este projeto que agora concluo. 


\section{RESUMO}

Empresas em cadeias de suprimentos têm como objetivo maximizar suas produtividades, e consequentemente seus lucros. Uma maneira de estudar o comportamento destas cadeias é simulá-las utilizando uma abordagem multi-agentes. Neste trabaIho, adicionamos múltiplos agentes nos níveis de um modelo amplamente adotado na literatura, denominado Beer Game, para avaliar a eficiência local e global dos fornecedores. Para tal, utilizamos perfis distintos baseados em confiança ou em preço. Medimos o impacto de usar tais políticas de seleção no capital acumulado pelos agentes, e concluímos que as parcerias baseadas em confiança são recomendáveis em cenários com ampla disseminação de informações verdadeiras, enquanto que as baseadas em lucro são mais vantajosas em cenários marcados por pouca comunicação ou pelo espalhamento de informações falsas.

Palavras-chave: Simulação baseada em multi-agentes, cadeias de suprimentos, confiança e reputação, Beer Game. 


\section{ABSTRACT}

Companies in supply chains have the objective of maximizing their productivities, and consequently their profits. A way of to study the behavior of these chains is to simulate them using a multi-agent-based approach. In this work, we added multiple agents at the levels of a widely adopted model in the literature, called Beer Game, to evaluate the local and global performance of suppliers. To do this, we use distinct profiles based on trust or price. We measure the impact of using such selection policies on the agents' profit, and we could conclude that trust-based partnerships are recommended in scenarios with wide dissemination of true information, while profit-based partnerships are most advantageous in scenarios marked by poor communication or spreading false information.

Keywords: Multi-agent-based simulation, supply chain, trust and reputation, Beer Game. 


\section{LISTA DE FIGURAS}

2.1 Exemplo de cadeia de suprimentos (LAMBERT; COOPER, 2000) . . . 17

2.2 Representação gráfica do BWE: tamanho médio do pedido crescente por nível da SC, do consumidor final até a fábrica (CHANG; YU; YANG, 2013) . . . . . . . . . . . . . . . . . . . . . 18

2.3 Disposição do tabuleiro para o Beer Game (STERMAN, 1992) ... . . 20

2.4 Demanda do consumidor final para o Beer Game (STERMAN, 1992) . . 22

4.1 Exemplo de possíveis escolhas de fornecedores de uma SC simulada na rodada inicial . . . . . . . . . . . . . . . . . . . . . 31

4.2 Parcelas do saldo de capital acumulado . . . . . . . . . . . . . . . . . 32

4.3 Novas escolhas de uma SC simulada, após troca de fornecedores . . . 42

5.1 Interface gráfica para o simulador ReLogo . . . . . . . . . . . . . . . . 44

5.2 Diferença entre taxas de sugestões baixa e alta . . . . . . . . . . . . . . . 48

5.3 Tamanho médio dos pedidos por nível da SC por rodada . . . . . . . . 48 


\section{LISTA DE TABELAS}

3.1 Comparativo entre publicações similares . . . . . . . . . . . . . . . . . . 29

4.1 Síntese das políticas de decisão $\ldots . . \ldots$. . . . . . . . . . . . . 37

5.1 Parâmetros de entrada . . . . . . . . . . . . . . . . . . . . . . 45

5.2 Lista de experimentos e parâmetros associados . . . . . . . . . . . . 46

5.3 Capital acumulado por taxa de sugestões $\epsilon \ldots \ldots$. . . . . . . . . 47

5.4 Pontualidade por taxa de sugestões $\epsilon \ldots \ldots$. . . . . . . . . 47

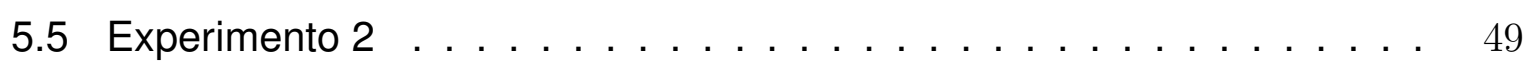

5.6 Capital acumulado por taxa de disseminação de reputação $\gamma$. . . . . . 49

5.7 Pontualidade por taxa de disseminação de reputação $\gamma \ldots$. . . . . . . . 50

5.8 Experimento $4 \ldots \ldots \ldots \ldots$. . . . . . . . . . . . . 50

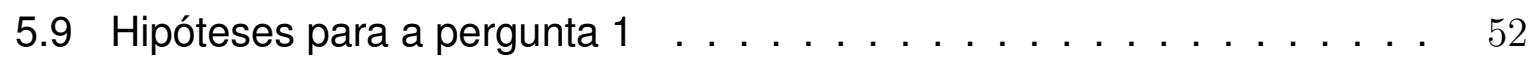

5.10 Hipóteses para a pergunta $2 \ldots \ldots \ldots$. . . . . . . . . . . 54

5.11 Hipóteses para a pergunta $3 \ldots \ldots \ldots$. . . . . . . . . . . 55

5.12 Hipóteses para a pergunta $4 \ldots \ldots$. . . . . . . . . . . 57 


\section{LISTA DE ALGORITMOS}

1 Beer Game-Fluxo . . . . . . . . . . . . . . . . . . . . . . . . . . . . . . 21

2 Ciclo de Simulação . . . . . . . . . . . . . . . . . . . . . . . . . . . . 34

3 Procedimento para escolha do fornecedor . . . . . . . . . . . . . . . 36 


\section{Lista de siglas}

A\&A anchoring and adjustment - ancoragem e ajuste

ABM agent-based modeling - modelagem baseada em agentes

ABS agent-based simulation - simulação baseada em agentes

BWE bullwhip effect - efeito chicote

CAS complex adaptive system - sistema complexo adaptativo

DSL domain specific language - linguagem específica de domínio

HM hybrid model - modelo híbrido

MAS multi-agent system - sistema multi-agentes

SC supply chain - cadeia de suprimentos

SCM supply chain management - gerenciamento de cadeia de suprimentos

SD $\quad$ system dynamics - dinâmica de sistemas 


\section{ÍNDICE}

1 Introdução 13

1.1 Motivação . . . . . . . . . . . . . . . . . . . . . . . . . . . . 14

1.2 Objetivo . . . . . . . . . . . . . . . . . . . . 14

1.3 Método . . . . . . . . . . . . . . . . . . . . . . 15

1.4 Organização do documento . . . . . . . . . . . . . . . . . . 16

2 Conceitos Básicos $\quad 17$

2.1 Cadeias de suprimentos . . . . . . . . . . . . . . . . . . 17

2.1 .1 Definição . . . . . . . . . . . . . . . . . . . . . 17

2.1 .2 Efeito Chicote . . . . . . . . . . . . . . . . . . . . . . . . 18

2.1.3 Estratégia de pedidos por ancoragem e ajuste . . . . . . . . . . 18

2.2 Beer Game . . . . . . . . . . . . . . . . . . . . . . . . . . . . . . . . . . 20

2.3 Simulação baseada em multi-agentes . . . . . . . . . . . . . . . . . . . 22

2.3.1 Agentes . . . . . . . . . . . . . . . . . . . . . 22

2.3.2 Confiança e reputação . . . . . . . . . . . . . . . . . . 23

2.4 Síntese . . . . . . . . . . . . . . . . . . . . . . 23

3 Estado da Arte $\quad 25$

3.1 Trabalhos relacionados . . . . . . . . . . . . . . . 25

3.2 Análise comparativa . . . . . . . . . . . . . . . . . . . 28

3.3 Síntese . . . . . . . . . . . . . . . . . . . . . . . . . . . . 29

4 Proposta $\quad 30$

4.1 Modelo de cadeia de suprimentos . . . . . . . . . . . . . . . . . . . 30

4.2 Modelo de agente . . . . . . . . . . . . . . . . . . . . . . . . . . . . 30

4.3 Modelo de capital financeiro . . . . . . . . . . . . . . . . . . . . . . 32

4.4 Modelo de confiança . . . . . . . . . . . . . . . . . . . . . . 33

4.5 Ciclo de simulação . . . . . . . . . . . . . . . . . . . . . . . 35

4.6 Perfis de agentes . . . . . . . . . . . . . . . . . . . . . . . 35

4.6.1 Agentes populares . . . . . . . . . . . . . . . . . . 35

4.6 .2 Agentes gananciosos . . . . . . . . . . . . . . . . 35

4.7 Políticas de decisão . . . . . . . . . . . . . . . . . . . . . . . . . . . 35

4.7.1 Escolha de fornecedor . . . . . . . . . . . . . . . . . 36 
4.7.2 Gerenciamento de estoque . . . . . . . . . . . . . . . . 36

4.7 .3 Controle de preço . . . . . . . . . . . . . . . . . . . . 37

4.7 .4 Síntese . . . . . . . . . . . . . . . . . . . . 37

4.8 Mecanismo de reputação . . . . . . . . . . . . . . . . . 37

4.9 Agentes sinceros e mentirosos . . . . . . . . . . . . . . . . . . . 38

4.10 Exemplo de ciclo de simulação . . . . . . . . . . . . . . . . . . . . . . . 39

4.11 Síntese . . . . . . . . . . . . . . . . . . . . 42

5 Implementação e Resultados $\quad 44$

5.1 Ambiente de simulação . . . . . . . . . . . . . . . . . . . . . . . . . . . 44

5.2 Parâmetros de entrada . . . . . . . . . . . . . . . . . . . . . . . . 45

5.3 Descrição dos experimentos . . . . . . . . . . . . . . . . 46

5.4 Resultados obtidos . . . . . . . . . . . . . . . . . . . . . . . . . 46

5.4.1 Experimento 1 - efeito de sugestões sinceras . . . . . . . . . . . 47

5.4.2 Experimento 2 - efeito de sugestões mentirosas . . . . . . . . . 48

5.4.3 Experimento 3 - efeito de reputações sinceras . . . . . . . . . . 49

5.4.4 Experimento 4 - efeito de reputações mentirosas . . . . . . . . . 50

5.5 Análise dos resultados . . . . . . . . . . . . . . . . . . . . . 51

5.5 .1 Método de análise . . . . . . . . . . . . . . 51

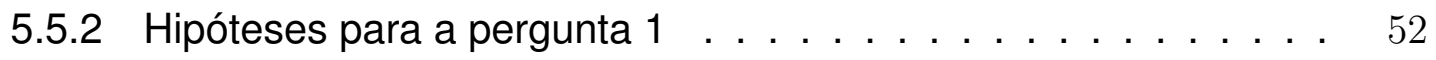

5.5 .3 Hipóteses para a pergunta $2 \ldots \ldots$. . . . . . . . . . 53

5.5 .4 Hipóteses para a pergunta $3 \ldots \ldots$. . . . . . . . . . . . . . . . . . . . . .

5.5 .5 Hipóteses para a pergunta $4 \ldots \ldots$. . . . . . . . . . . 55

5.6 Síntese . . . . . . . . . . . . . . . . . . 57

6 Conclusões $\quad 59$

$\begin{array}{ll}\text { Referências } & 60\end{array}$ 


\section{Introdução}

O objetivo principal de qualquer negócio é maximizar seu lucro (FRIEDMAN, 2007). Contudo, existem múltiplas formas de se atingir este objetivo, dentre elas a redução de custos operacionais e de inventário, do tempo de ciclo de produção, da probabilidade de ruptura (falta de estoque), bem como o aumento da taxa de entrega de pedidos (BEAMON, 1999).

Para atingir tais níveis de excelência, é comum empresas interagirem formando uma cadeia de suprimentos $(\mathrm{SC})^{1}$. O gerenciamento eficiente e eficaz dos fluxos de materiais ao longo de uma SC é fundamental para seu sucesso (HANDFIELD; NICHOLS, 1999). O estudo do gerenciamento destas cadeias(SCM) ${ }^{2}$ tem por objetivo otimizar todo o sistema (SIMCHI-LEVI; KAMINSKY; SIMCHI-LEVI, 2000), e vem sendo alvo de interesse crescente visando obter vantagens competitivas para o mercado por meio de melhorias em seus processos (CROOM; ROMANO; GIANNAKIS, 2000).

Em qualquer SC, entidades individuais são interligadas por logística, informação e fluxo financeiro e devem, portanto, cooperar e competir entre si. Como resultado, a interação entre as entidades na cadeia de suprimentos é intensa, e a decisão de uma empresa pode causar mudanças que afetam tanto a si própria quanto a todas as outras entidades da SC. Assim, o status financeiro de uma empresa da SC depende não apenas de suas próprias habilidades de gerenciamento, mas também das decisões gerenciais e operacionais dos parceiros vinculados (HUA; SUN; XU, 2011).

Swaminathan, Smith e Sadeh (1998) propõem simular SCM com o auxílio de simulação baseada em multi-agentes (MABS) ${ }^{3}$, ressaltando a importância de adotar modelos em que cada entidade da cadeia opera sujeita às próprias restrições e objetivos, e tem sua própria visão de mundo, o que permite que o desempenho da cadeia seja avaliado sob perspectivas organizacionais distintas.

Fuente e Lozano (2007) defendem tal escolha baseados nas características intrínsecas do SCM: é um problema fisicamente distribuído, pode ser alimentado com um padrão geral de tomada de decisões, cada agente pode considerar tanto interesses próprios como de toda a cadeia, além de se tratar de um problema altamente complexo, influenciado pela interação entre as diversas variáveis que o integram.

\footnotetext{
Do inglês supply chain.

2 Do inglês supply chain management.

3 Do inglês multi-agent-based simulation.
} 
Já Choi, Dooley e Rungtusanatham (2001) argumentam que as redes da cadeia de suprimentos são sistemas adaptativos inerentemente complexos, muitos dos quais simplesmente emergem em vez de serem engendrados a partir do projeto intencional de uma entidade singular.

Similarmente, Zee e Vorst (2005) embasam a escolha na flexibilidade que esta abordagem oferece para a modelagem e estudo de SCs, cuja complexidade intrínseca obstrui qualquer tentativa de avaliação analítica.

\subsection{Motivação}

A otimização do desempenho em uma SC pode ser bastante difícil de ser alcançada porque diferentes membros da cadeia têm objetivos conflitantes (SIMCHI-LEVI; KAMINSKY; SIMCHI-LEVI, 2000). Levando isso em conta, parcerias baseadas em relações de confiança podem ser mais lucrativas do que aquelas baseadas em apenas em mecanismos de oferta e demanda.

Tal hipótese tem por base a comprovação de que quanto maior a confiança de um consumidor em seus fornecedores, maior a responsividade e pontualidade destes, e portanto maior o ganho para a SC (HANDFIELD; BECHTEL, 2002). Como uma forma importante de capital relacional, a confiança é fundamental para mitigar riscos de interação e gerar cooperação porque reduz a incerteza das ações e comportamento oportunista dos parceiros (YEUNG et al., 2009; WANG; YEUNG; ZHANG, 2011). Oportunismo inclui mentir e trapacear, bem como violar acordos implícitos (RINDFLEISCH; HEIDE, 1997).

Ainda, evidências empíricas demonstram que a confiança entre parceiros pode reduzir a variabilidade dos seus níveis de estoque (PANAYIDES; LUN, 2009), e também indicam que a confiança entre fornecedores e consumidores contribui para uma maior integração da cadeia, o que por sua vez aumenta seu ganho financeiro (ZHANG; HUO, 2013).

Apesar de haver muitos estudos acerca do impacto da confiança em SCM, conforme discutido acima, a maior parte dos resultados baseia-se em questionários. Por sua vez, o uso de MABS ainda é relativamente escasso nesse domínio, em especial quando se pretende mensurar o desempenho individual e conjunto dos agentes, uns buscando credibilidade, outros movidos por oportunismo.

\subsection{Objetivo}

O presente trabalho tem por objetivo analisar o impacto da confiança e troca de informações entre entidades inseridas no contexto de uma cadeia de suprimentos simu- 
lando empresas com perfis de atuação distintos interagindo entre si. Desta forma será possível avaliar o desempenho individual médio dos agentes que priorizam pontualidade (denominados populares) em relação aos que priorizam margem de lucro por transação (denominados gananciosos), em cenários com níveis distintos de perguntas e sugestões, de disseminação de reputações e de informações falsas.

Para tal, adota-se uma abordagem de MABS, utilizando um modelo de SC amplamente adotado na literatura, denominado Beer Game (STERMAN, 1992).

$O$ estudo visa responder às seguintes perguntas:

1. O tipo de estratégia adotada pelos agentes afeta o capital acumulado e a pontualidade de suas entregas?

2. A troca de sugestões de fornecedores entre clientes afeta o capital acumulado e a pontualidade de entrega dos agentes?

3. A presença de agentes mentirosos tem efeito no capital acumulado e na pontualidade de entrega dos agentes?

4. A disseminação de reputação tem efeito no capital acumulado e na pontualidade de entrega dos agentes?

\subsection{Método}

A elaboração deste trabalho obedece à seguinte sequência de etapas, proposta inicialmente em (JALBUT; SICHMAN, 2016):

1. Em primeiro lugar, realiza-se um estudo bibliográfico cuja intenção é detalhar os estudos mais significativos que simulam por MABS as relações de confiança entre clientes e fornecedores participantes de uma SCM;

2. Reunem-se então elementos encontrados nesses estudos para a elaboração de um modelo de SC integrada por agentes que obedecem às regras do Beer Game (seção 2.2);

3. Em seguida, implementa-se esse modelo utilizando um ambiente de programação adequado para esta tarefa;

4. Definem-se então os cenários dos experimentos, de forma a responder às perguntas de pesquisa por meio da definição das combinações de parâmetros de entrada e da fixação das demais variáveis do modelo; 
5. Executam-se os referidos experimentos, cujos resultados são então estatisticamente validados via testes de hipóteses;

6. Por fim, traçam-se as conclusões a partir dos resultados validados.

\subsection{Organização do documento}

Além deste capítulo introdutório, este documento outros 5 (cinco) capítulos adicionais:

- Capítulo 2 - Conceitos Básicos: introduz os conceitos essenciais relacionados ao trabalho: cadeias de suprimentos, Beer Game, ancoragem e ajuste, simulação baseada em agentes, confiança e reputação;

- Capítulo 3 - Estado da Arte: enumera alguns dos trabalhos mais significativos e atuais no contexto deste trabalho, resumindo sua contribuição;

- Capítulo 4 - Proposta: apresenta o objeto deste estudo, detalhando o modelo utilizado para os agentes, seus perfis de atuação, seus objetivos e estratégias de decisão;

- Capítulo 5 - Implementação e Resultados: apresenta o ciclo de simulação, seus parâmetros e o ambiente em que ela se insere, e também descreve e analisa os experimentos realizados.

- Capítulo 6 - Conclusões: traz as conclusões obtidas através dos experimentos e também apresenta sugestões para trabalhos futuros. 


\section{Conceitos Básicos}

Esta pesquisa é fundamentada em uma série de conceitos pertinentes às áreas de SCM e MABS, descritos neste capítulo.

\subsection{Cadeias de suprimentos}

\subsubsection{Definição}

Cadeias de suprimentos são definidas como o conjunto de organizações, atividades, informação e recursos envolvidos na movimentação de um produto ou serviço de fornecedor para consumidor (NAGURNEY, 2006). O estudo do gerenciamento destas cadeias $(\mathrm{SCM})^{1}$ vem sendo alvo de interesse crescente visando obter vantagens competitivas para o mercado por meio de melhorias em seus processos (CROOM; ROMANO; GIANNAKIS, 2000). A Figura 2.1 (LAMBERT; COOPER, 2000) ilustra um exemplo de uma SC.

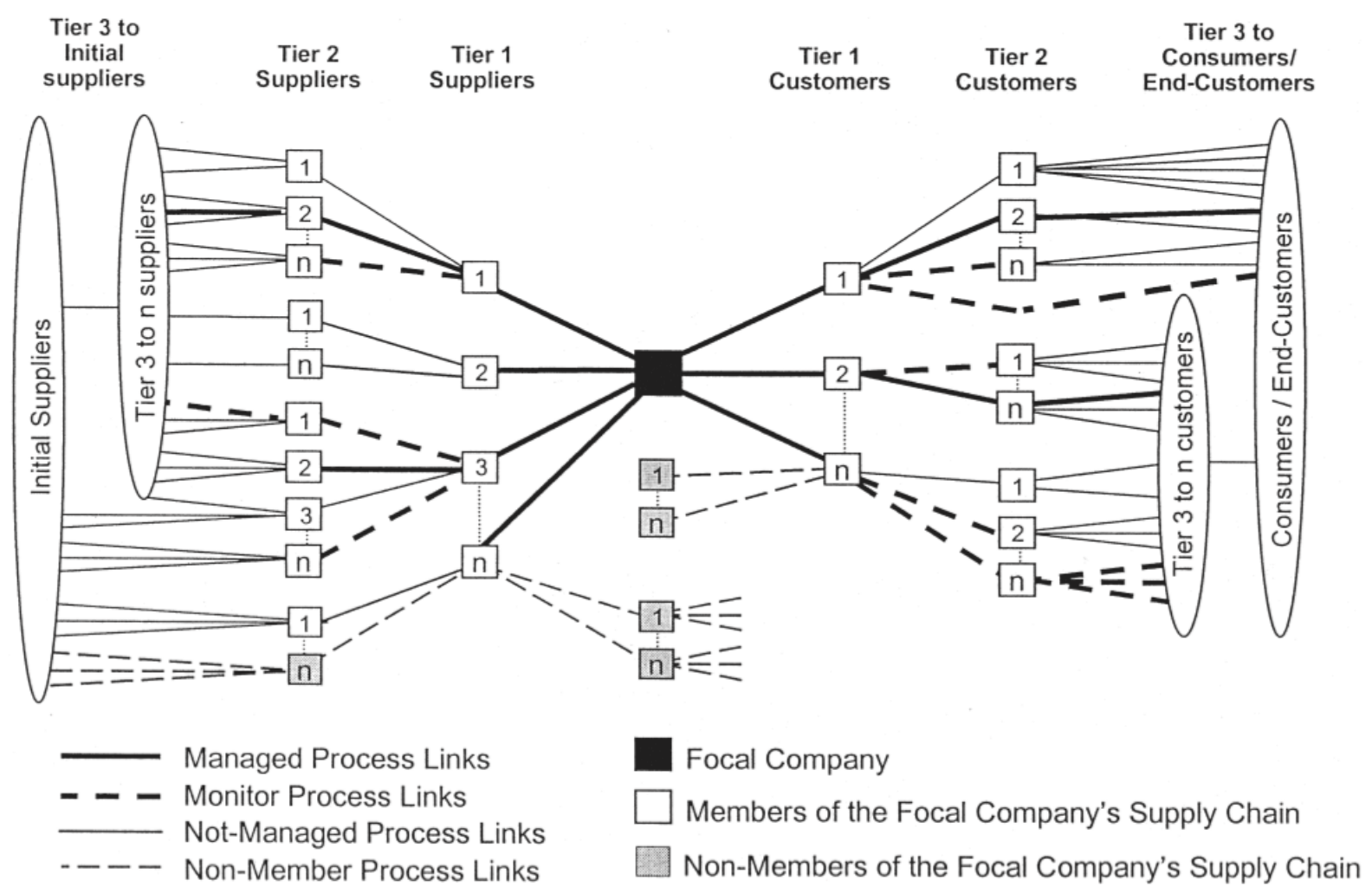

Figura 2.1 - Exemplo de cadeia de suprimentos (LAMBERT; COOPER, 2000)

1 Do inglês supply chain management. 


\subsubsection{Efeito Chicote}

O efeito chicote (BWE) ${ }^{2}$, descrito inicialmente por Forrester (1997), é um fenômeno que ocorre em SCs. Consiste na amplificação da variância dos pedidos feitos entre os níveis da cadeia, no sentido do consumidor final para a fábrica, conforme ilustrado pela Figura 2.2. Este efeito, demonstrado matematicamente por Lee, Padmanabhan e Whang (1997), é, segundo estes autores, responsável por aumentos drásticos em custos, entre eles o de matéria prima, o de manufatura, armazenamento e transporte.

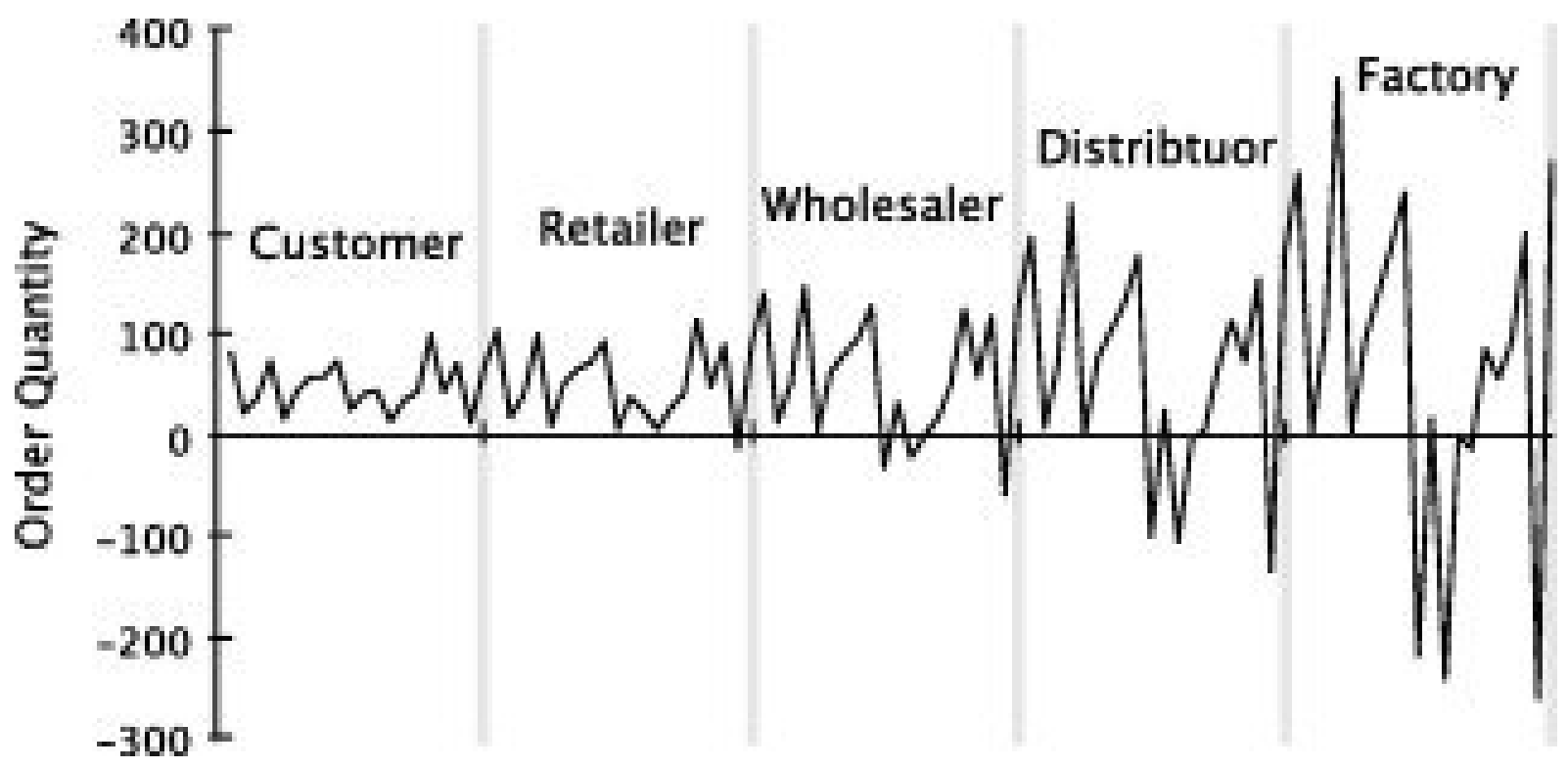

Figura 2.2 - Representação gráfica do BWE: tamanho médio do pedido crescente por nível da SC, do consumidor final até a fábrica (CHANG; YU; YANG, 2013)

\subsubsection{Estratégia de pedidos por ancoragem e ajuste}

Dinâmica de sistemas (SD) ${ }^{3}$ é uma abordagem proposta por Jay Forrester em meados da década de 1950, inicialmente sob o nome de dinâmica industrial (FORRESTER, 1997), para modelar o comportamento dinâmico de sistemas complexos através de uma perspectiva baseada em realimentação de informação e atrasos, que são representados por fluxos e pontos de acumulação de informação, dinheiro, pedidos, materiais e equipamentos (ANGERHOFER; ANGELIDES, 2000).

Uma das primeiras aplicações desta abordagem foi o problema de gerenciamento de estoques em SCM (FORRESTER, 1997), em que pedidos e carregamentos entre entidades da SC são mapeados para fluxos, e o estoques armazenados por cada entidade mapeados para acumuladores.

\footnotetext{
2 Do inglês bullwhip effect

3 Do inglês system dynamics.
} 
Sob a ótica de SD, Sterman (1987) propõe uma fórmula para modelar a forma como companhias dimensionam pedidos a fornecedores a fim de controlar seus próprios níveis de estoque baseando-se no mecanismo cognitivo de ancoragem e ajuste $(A \& A)^{4}$ descrito por Tversky e Kahneman (1974).

O autor propõe como heurística que pedidos aos fornecedores devem ser definidos de modo a:

1. ressuprir perdas esperadas do estoque;

2. reduzir a discrepância entre o estoque atual e o desejado;

3. manter uma linha de suprimento adequada para os pedidos já feitos mas ainda não recebidos.

A estratégia para calcular a diferença $I O_{t}$ no estoque desejado no instante $t$ é traduzida na Equação 2.1, em que o pedido a ser feito é obtido pela soma de três parcelas, detalhadas adiante.

$$
I O_{t}=L e_{t}+A S_{t}+A S L_{t}
$$

- $L e_{t}$ são as perdas esperadas, calculadas por atenuação exponencial, conforme a Equação 2.2.

$$
L e_{t}=\Theta L_{t-1}+(1-\Theta) L e_{t-1}, 0<\Theta<1
$$

onde $L_{t-1}$ são as perdas reais na rodada $\mathrm{t}-1$.

- $A S_{t}$ é o ajuste do estoque, obtido da Equação 2.3.

$$
A S_{t}=\alpha_{s}\left(S *-S_{t}\right), 0<\alpha s<=1
$$

onde $S *$ é o estoque desejado,e $S_{t}$ é o estoque em mãos no instante $t$

- $A S L_{t}$ é o ajuste na linha de suprimento (conjunto de pedidos enviados e carregamentos a receber), que resulta da Equação 2.4.

$$
A S L_{t}=\alpha_{s L}\left(S L *-S L_{t}\right), 0<\alpha s L<=1
$$

onde $S L *$ é a linha de suprimento desejada e $S L_{t}$ é linha de suprimento no instante $t$

4 Do inglês anchor and adjustment. 
Por fim, a quantidade $O_{t}$ pedida nunca deve ser negativa, o que é expresso pela Equação 2.5, que recebe $I O_{t}$ como parâmetro.

$$
O_{t}=\operatorname{MAX}\left(0, I O_{t}\right)
$$

\subsection{Beer Game}

O Beer Game ${ }^{5}$ é um jogo de tabuleiro projetado por Forrester na década de 1960 para entender SCM e demonstrar o BWE na prática (STERMAN, 1992). Nele, dois times de 4 jogadores competem entre si, cada time representando uma cadeia de suprimentos. Em cada time, cada membro exerce o papel de um dos 4 níveis de uma SCM: fábrica, distribuidor, atacadista e revendedor. O objetivo do jogo é gerenciar o estoque em face de demanda externa desconhecida, e o time vencedor é aquele que obtiver menores custos acumulados na soma dos níveis da cadeia.

Cada equipe participante tem à sua disposição seu próprio tabuleiro. Nele, cada nível da cadeia tem seu estoque e carregamentos a receber representados por marcadores, e pedidos anotados em folhas de papel viradas para baixo, como mostra a Figura 2.3.

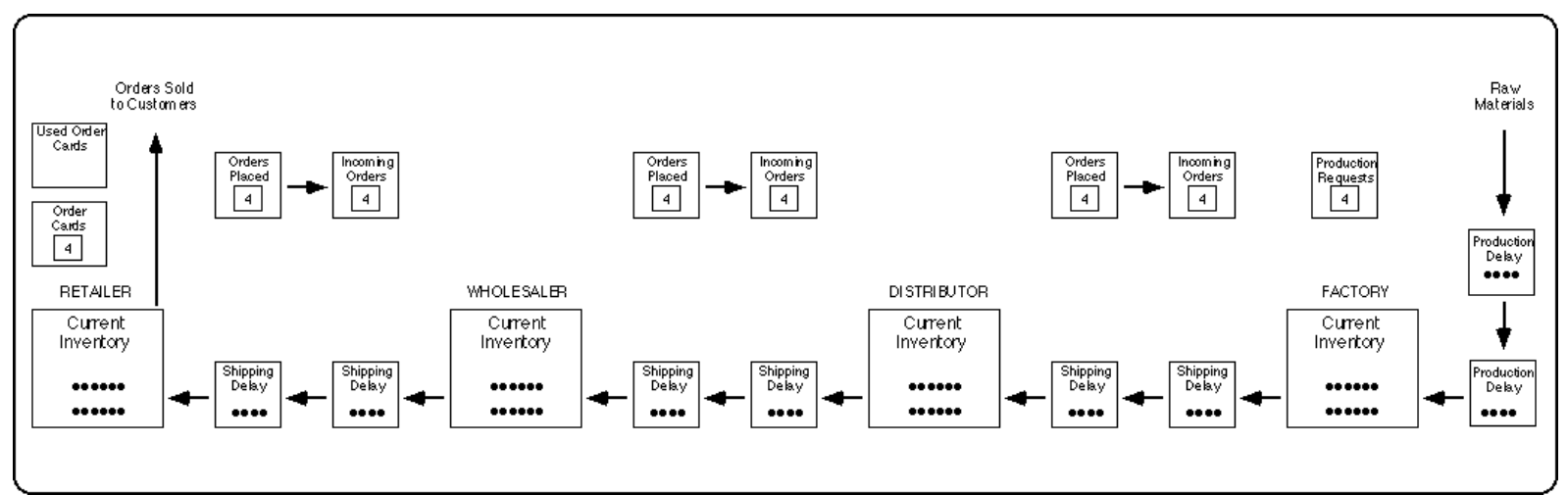

Figura 2.3 - Disposição do tabuleiro para o Beer Game (STERMAN, 1992)

Pedidos demoram uma rodada para chegar ao destinatário. Cada jogador dimensiona e envia pedidos para o jogador que controla o nível superior, exceto a fábrica, que envia ordens para sua própria linha de produção. Cada jogador também recebe e deve atender aos pedidos recebidos do nível inferior, exceto o revendedor, que obtém seus pedidos de uma pilha de papéis virados para baixo. Esta pilha representa a demanda do consumidor final e possui a mesma ordenação e valores para todos os grupos.

Carregamentos demoram duas rodadas para chegar ao destinatário. Cada jogador retira de seu estoque e envia carregamentos para atender aos pedidos do jogador que

5 Traduzindo: jogo da cerveja 
controla o nível inferior. Cada jogador também recebe os carregamentos enviados pelo nível superior e os deposita em seu próprio estoque, exceto a fábrica, que recebe os carregamentos de sua própria linha de produção. Caso um jogador não disponha de estoque suficiente para atender o último pedido recebido, ele envia um carregamento com o restante do seu estoque, e a parcela devida é anotada para ser enviada na próxima rodada, somada ao próximo pedido a ser satisfeito.

O jogo ocorre em um número fixo de rodadas, tipicamente 36 , sendo que em cada uma delas ocorre uma sequência de ações que devem ser executadas simultaneamente por todos os membros de todos os grupos. Esta sequência é descrita no Algoritmo 1.

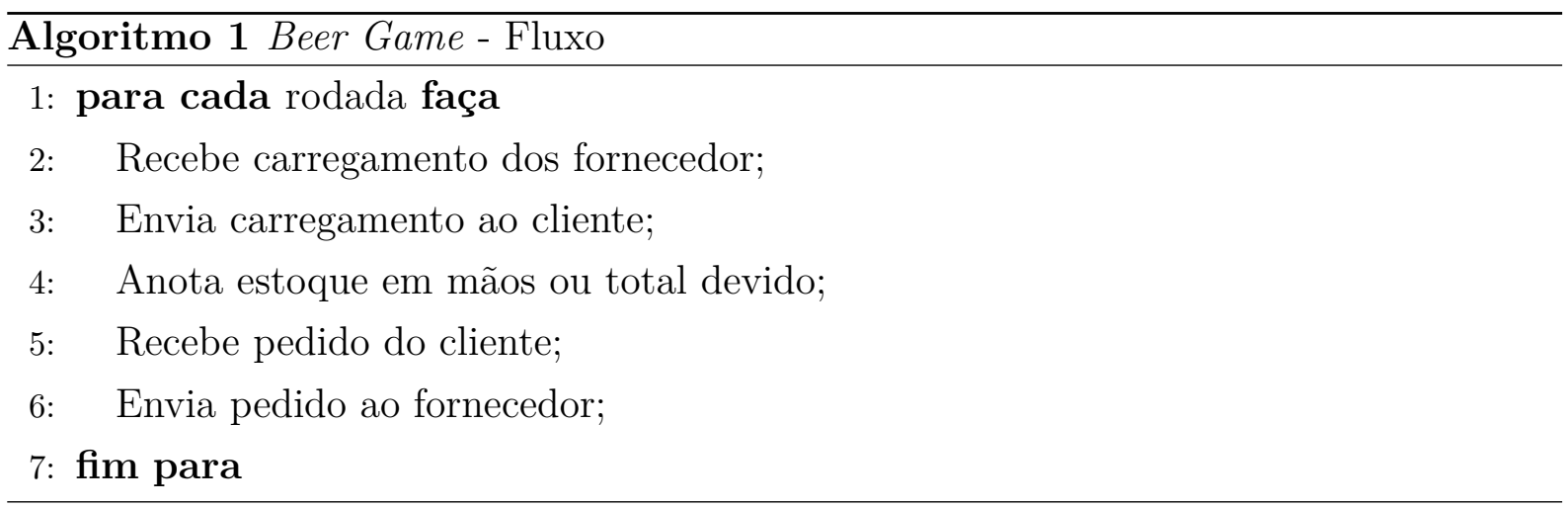

Ao final da 36 rodada, o jogo é encerrado, e o grupo vencedor é determinado como sendo aquele que tiver acumulado, em todos os seus níveis e rodadas, a menor pontuação conforme definido na Equação (2.6).

$$
\text { pontuação }=0.5 * \text { estoque em mãos }+1 * \text { total devido }
$$

A demanda do consumidor é conhecida pelos jogadores após o encerramento: é fixa em 4 unidades por rodada até a $4^{\mathrm{a}}$ rodada, e em 8 unidades por rodada da $5^{\mathrm{a}}$ rodada em diante, como ilustra a Figura 2.4. Tendo-a como parâmetro, é possível observar o efeito chicote, com oscilações significativamente maiores em estoque e nos pedidos feitos entre os níveis superiores, e crescendo no sentido da fábrica (STERMAN, 1989), como ilustra a Figura 2.2. 


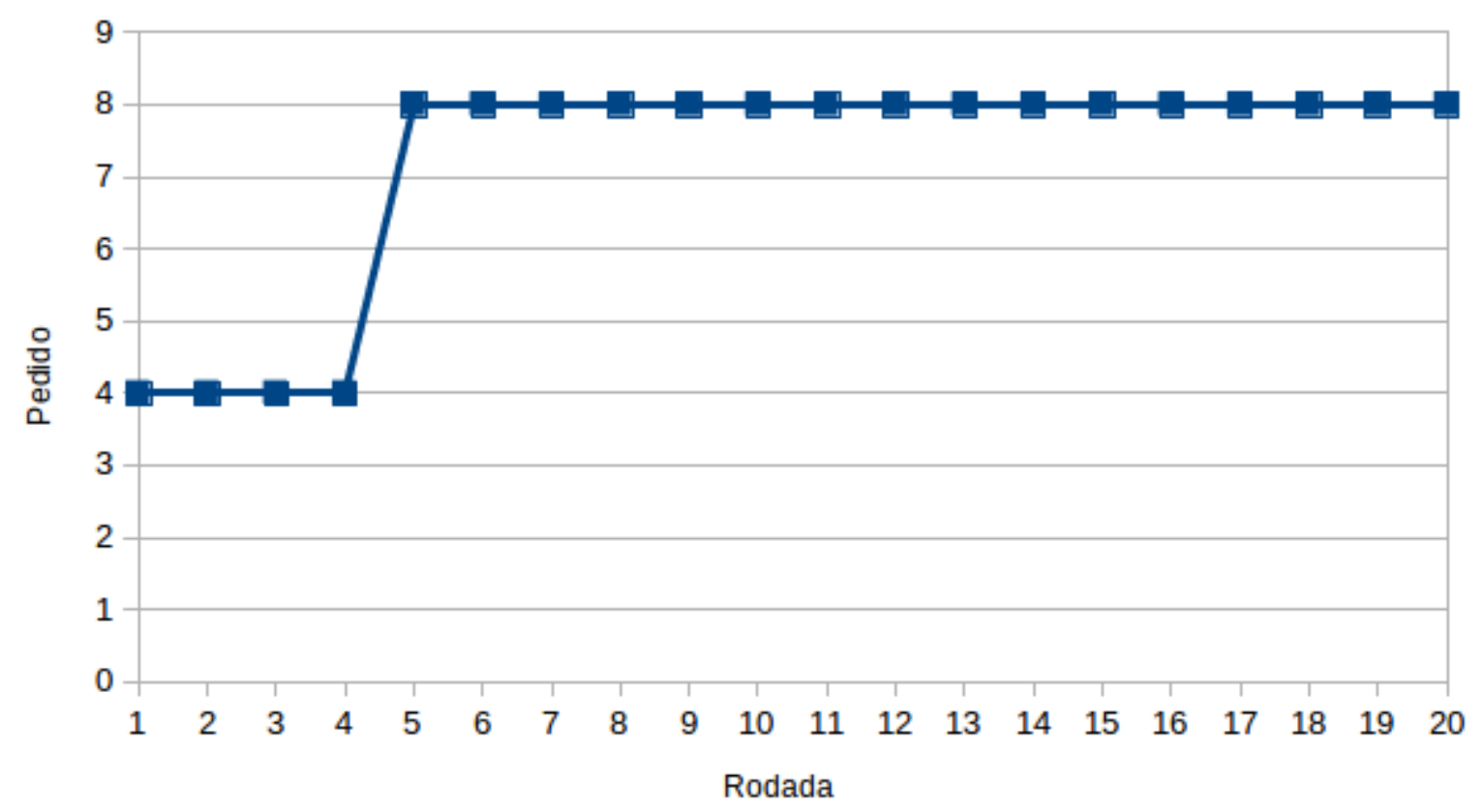

Figura 2.4 - Demanda do consumidor final para o Beer Game (STERMAN, 1992)

\subsection{Simulação baseada em multi-agentes}

Uma forma de se estudar o comportamento de sistemas é por meio de simulação baseada em agentes (MABS), definidos abaixo.

\subsubsection{Agentes}

Holland e Miller (1991) propõe a análise de sistemas econômicos através do que definem como sistemas adaptativos complexos $(\mathrm{CAS})^{6}$. Tais sistemas têm as seguintes características:

1. possuem múltiplos agentes interagindo entre si;

2. exibem um comportamento dinâmico agregado resultante da interação entre os agentes, que pode ser descrito sem o conhecimento detalhado do comportamento de cada agente;

3. são compostos por agentes adaptativos, ou seja, agentes a cujas ações pode ser atribuído um valor (utilidade, ganho) e que agem para maximizar este valor;

Parunak (1997) equipara CAS ao que hoje conhecemos pelo nome de sistemas multiagentes (MAS) ${ }^{7}$. Este é um ramo da inteligência artificial que estabelece a represen-

\footnotetext{
6 Do inglês complex adaptive systems.
}

7 Do inglês multi-agent systems. 
tação de um sistema como a interação entre múltiplos agentes inteligentes, cada um avaliando alternativas diferentes e tomando suas próprias decisões, dentro de um contexto definido por restrições locais e externas (WOOLDRIDGE, 2000). Deste modo, é possível modelar uma SC como a interação entre vários agentes, cada um guiado por seu próprio objetivo estratégico.

\subsubsection{Confiança e reputação}

Define-se confiança como a predisposição de um agente a se colocar em uma posição vulnerável com relação a outro esperando que este lhe proporcione alguma vantagem por contrapartida (MAYER; DAVIS; SCHOORMAN, 1995). Em geral, a confiança é um produto acumulado de repetidas interações passadas entre as partes, através das quais elas passam a se entender e a desenvolver um conhecimento comum de compromissos mútuos (RING; VEN, 1994). Esse mecanismo desempenha um papel crucial no desenvolvimento de qualquer relacionamento de longo prazo (MORGAN; HUNT, 1994) e é especialmente importante em parcerias estratégicas (IRELAND; WEBB, 2007). No contexto de SCM, iniciativas de empresas para construir e fomentar a confiança com seus parceiros são necessárias, uma vez que uma SC é composta por firmas individuais colaborando para servir consumidores finais e sua eficácia é altamente dependente da confiança entre essas firmas (VLACHOS; BOURLAKIS, 2006).

Normalmente, a confiança entre agentes aumenta ou diminui em função de suas interações bem ou mal sucedidas. Entretanto, uma escolha de parceria numa primeira interação pode ocorrer por indicação ou por meio da reputação.

De acordo com Giardini, Tosto e Conte (2008), reputação é um fenômeno distinto, embora inter-relacionado com o que chamam de imagem. Mais precisamente, imagem é um conjunto de crenças valorativas sobre um determinado alvo, enquanto reputação é tanto o processo quanto o efeito da transmissão de uma imagem. A característica distintiva da reputação é a falta de uma fonte identificada, isto é, sua impessoalidade. A reputação não pode ser atribuída a alguém, mas é algo que "as pessoas dizem" sobre alguém, sem explicitar a fonte da avaliação.

\subsection{Síntese}

Neste capítulo, foram descritos os principais conceitos que embasaram a elaboração do presente trabalho. Na seção 2.1 foram apresentadas as cadeias de suprimentos (SC), o efeito chicote (BWE), comumente verificado em muitas delas, a área de dinâmica de sistemas (SD) e a estratégia de pedidos por ancoragem e ajuste (A\&A) 
definida dentro de SD. Em seguida, detalhou-se o Beer Game, jogo projetado para simular o BWE em SCs, cujas regras foram detalhadas na seção 2.2. Na sequencia, a simulação baseada em multi-agentes (MABS) foi apresentada na seção 2.3, inserida num contexto de SCM, e por fim foram introduzidos os conceitos de confiança e reputação de agentes.

Apresentados esses conceitos, será detalhado no Capítulo 4 como utiliza-se MABS para simular as interações e relações de confiança entre clientes e fornecedores numa SC operando sob as regras do Beer Game. Entretanto, antes de detalhar esta proposta, o estado da arte é apresentado na sequência. 


\section{Estado da Arte}

Neste capítulo, os principais trabalhos relacionados são apresentados, comparados e sintetizados, de forma a extrair do conjunto resultante elementos para o presente modelo, assim como identificar lacunas de pesquisa. Buscam-se estudos que apresentem algumas ou todas as seguintes características:

- Inserem-se no campo de SCM;

- Têm por estratégia a simulação via MABS;

- Abordam algum mecanismo de confiança ou avaliação de desempenho para escolha e mudança de fornecedores;

- Fazem uso do modelo do Beer Game, A\&A, ou de SD em geral.

\subsection{Trabalhos relacionados}

Existem alguns estudos que abordam as três primeiras características da lista acima, dentre os quais é possível destacar seis: Akkermans (2001), Schieritz e Größler (2003), Lin, Sung e Lo (2005), Giardini, Tosto e Conte (2008), Kim (2009), Hou et al. (2014). Estes estudos subdividem-se em dois grupos: aqueles cujo modelo de agente é baseado em SD, e os demais, que possuem modelo de agente próprio.

À época da virada do milênio, Phelan (1999) e Scholl (2001) expõem que a abundância de pesquisas feitas até então nas áreas de SD (seção 2.1.3) e MABS (seção 2.3) contrastava com a escassez de trabalhos combinando as duas abordagens, os chamados modelos híbridos $(\mathrm{HM})^{1}$. Segundo estes autores, o diálogo entre estas frentes de estudo é relevante e potencialmente esclarecedor porque ambas miram nos mesmos objetos, sistemas complexos, mas sob óticas complementares: enquanto SD projeta o comportamento individual de seus elementos básicos a partir das propriedades globais de um sistema, MABS parte da definição individual de regras para os agentes, que interagem e fazem emergir o comportamento global do sistema em que se inserem.

Já Parunak, Savit e Riolo (1998) apontam duas formas de integrar MABS e SD:

1. Um agente é modelado pelas equações de SD;

1 Do inglês hybrid models. 
2. Um agente faz parte de um sistema modelado via SD.

Lattila, Hilletofth e Lin (2010) enumeram os principais trabalhos envolvendo HM simulados até então. Dentre eles, estão Akkermans (2001) e Schieritz e Größler (2003), que seguem a segunda abordagem de Parunak, e, por também incorporarem aspectos de confiança, são detalhados a seguir.

Nas simulações de SCM feitas em Akkermans (2001), relações emergem a partir das preferências de agentes, subdivididos entre aqueles que priorizam desempenho a curto prazo de seus clientes e fornecedores, aqueles que priorizam o longo prazo, e aqueles que priorizam tanto o curto quanto o longo prazo. É o único dentre os estudos destacados a utilizar políticas de decisão heterogêneas dentro de uma mesma simulação. O estudo obtém duas conclusões: a primeira é que SCs estáveis surgem espontaneamente a partir de quando as preferências específicas por clientes e fornecedores começam a divergir, o que ocorre quando a rede é sobrecarregada pela primeira vez, seja por um aumento drástico de produção, seja por uma queda considerável nos pedidos, e a partir daí estas preferências não se alteram. A segunda conclusão é que, em geral, costuma ser proveitoso priorizar o desempenho a curto prazo, uma vez que, conforme demonstram os experimentos, os agentes com esta política decisória apresentam melhor desempenho que os demais, em especial entre os clientes.

Em estudo similar, Schieritz e Größler (2003) também analisam a formação e mudanças de parcerias na SC, desta vez aplicando a mesma política decisória a todos os agentes, e variando esta política entre experimentos, padrão este que se repete para os estudos listados em sequência. Ao contrário do observado em Akkermans (2001), as mudanças de fornecedor não se estabilizam no decorrer das simulações. Os autores observam que as cadeias apresentam menos trocas de fornecedores quando seus agentes são governados por uma política focada em desempenho a longo prazo, em comparação ao que ocorre quando são programados para privilegiar o curto prazo. A diferença entre os dois trabalhos evidencia a dependência entre as decisões de modelagem e a natureza dos resultados obtidos pela simulação de cada modelo.

Em outra série de experimentos, Schieritz e Größler (2003) comparam estratégias de atendimento de pedidos, verificando que privilegiar as entregas aos clientes mais confiáveis, ou seja, aqueles com maior histórico de pedidos, tende a gerar parcerias mais estáveis que atender os pedidos pela ordem em que são recebidos.

Antes de analisar o próximo trabalho, convém destacar o trabalho de Kimbrough, Wu e Zhong (2002), que usam agentes computacionais para simular o comportamento de seres humanos participantes do Beer Game. Conforme indicam seus experimentos, os agentes jogam de forma efetiva, tanto em cenários de demanda externa deter- 
minística quanto de demanda estocástica, adaptando-se rapidamente no decorrer da simulação e encontrando em poucos passos as políticas de ressuprimento tidas como ótimas.

Este estudo serviu de referência a Kim (2009), que combina SC, Beer Game e confiança em um mesmo HM. Utilizando a plataforma REPAST (COLLIER, 2003), o autor simula uma cadeia de suprimentos com cinco níveis de agentes, sendo os quatro do Beer Game somados ao consumidor final, mas considerando que existem 3 três agentes por nível. Cada agente pertencente a certo nível da SC distribui seus pedidos entre os agentes do nível superior, e seus carregamentos entre os agentes do nível inferior, tudo isto respeitando uma política de decisão comum a todos os agentes. O autor propõe e compara duas políticas: BACKORDER, em que cada cliente pede mais a quem menos lhe deve e cada fornecedor entrega mais a quem mais deve, e TRUST, em que cada cliente pede mais a quem mais lhe entrega pontualmente, e cada fornecedor entrega mais a quem mais lhe pede. Constata que o uso de TRUST tende a estabilizar os estoques dos agentes no decorrer dos experimentos, ao contrário do que ocorre com BACKORDER, em que oscilações persistem até o término das simulações.

Lin, Sung e Lo (2005) implementam um modelo de confiança para os contratos de fornecimento em uma SC simulada na plataforma SWARM (MINAR, 1996). Seu modelo de fornecedor é baseado na combinação de três atributos: habilidade (nível de competência do contratado), benevolência (disposição do contratado a fazer concessão de data de entrega ao contratante) e integridade (chance de o contratado honrar o contrato). Os autores realizam três baterias de experimentos: a primeira delas varia a quantidade e espaçamento dos pedidos, a segunda varia a propensão de um cliente a confiar em um fornecedor, e a terceira varia o peso de cada um dos três fatores acima no nível de confiança total. A partir dos resultados destas baterias, eles depreendem que, de forma geral, a utilização do referido mecanismo de confiança pelos clientes, em detrimento de avaliar apenas o preço e data de entrega ofertados pelos fornecedores, reduz o tempo de ciclo e aumenta a taxa de pedidos entregues pontualmente, mas em compensação aumenta o preço médio negociado.

Em um abordagem complementar, Giardini, Tosto e Conte (2008) modelam as relações entre empresas enfocando os elos sociais entre os agentes. Dentro desta estrutura, as avaliações sociais são os blocos de construção das relações dentro da SC, usados para selecionar parceiros confiáveis, criar e ampliar a rede social e exercer controle social sobre os trapaceiros. Os autores implementam, como diferencial, a possibilidade de agentes do mesmo nível da SC trocarem sugestões de fornecedor. Com isso, procuram avaliar o impacto das recomendações na qualidade dos 
fornecedores escolhidos e no capital acumulado obtido por meio dessas escolhas. Introduzem, ainda, cenários com agentes mentirosos que fazem recomendações falsas a quem lhes pergunta, comparando a cenários compostos integralmente por agentes sinceros.

Hou et al. (2014) investigam, em vez da variação de estoques, o acúmulo de capital financeiro em uma SC sujeita à entrada e saída de novas companhias. O estudo é fundamentado no modelo de Mizgier, Wagner e Holyst (2012), que incorpora variáveis e políticas de decisão financeiras ao modelo dos agentes, dentre elas faixas de preços de venda geradas por distribuições estatísticas, uma para cada nível da SC. Em seu estudo, o autor avalia o uso pelos agentes da SC de um mecanismo de confiança de própria autoria. Em simulações distintas, testa a adoção conjunta dos agentes de três estratégias distintas para escolha de fornecedor: uma baseada no mecanismo proposto, outra baseada em preço e ainda uma terceira, randômica. Seus resultados indicam que o uso de confiança tende a maximizar o acúmulo de capital considerando a cadeia como um todo.

\subsection{Análise comparativa}

Os principais trabalhos relacionados são listados na Tabela 3.1, juntamente com seu modelo de agentes, o indicador de desempenho que condiciona as escolhas de fornecedores, a função de utilidade comparada no estudo e as políticas de decisão testadas para os agentes. Constata-se, ao analisar os trabalhos mais compatíveis com o problema de pesquisa, alguns pontos relevantes:

- Modelo de agentes: Três dos estudos usam HM com agentes modelados via SD: Akkermans (2001), Schieritz e Größler (2003), e Kim (2009), mas apenas o último adere às regras do Beer Game, cujo modelo já é consolidado (EDALI; YASARCANB, 2014) e empiricamente validado (STERMAN, 1992);

- Indicador de desempenho: Todos os estudos condicionam o desempenho de um fornecedor à quantidade e/ou agilidade/pontualidade de suas entregas. Existe um consenso com relação a este ponto;

- Políticas dos agentes: Apenas Akkermans (2001) usa políticas de decisão heterogêneas em uma mesma SC simulada, variando a preferência entre os clientes entre foco em desempenho a curto ou a longo prazo para os respectivos fornecedores. A literatura é, em geral, escassa no que diz respeito à interação entre agentes de perfis distintos; 
- Função de utilidade: Todos os estudos analisam o impacto da atuação dos agentes sob o ponto de vista global da SC, mas nenhum deles aborda o desempenho individual de cada um.

Tabela 3.1 - Comparativo entre publicações similares

\begin{tabular}{|l|l|l|l|l|}
\hline Estudo & $\begin{array}{l}\text { Modelo de } \\
\text { agentes }\end{array}$ & $\begin{array}{l}\text { Indicador de } \\
\text { desempenho }\end{array}$ & $\begin{array}{l}\text { Políticas dos } \\
\text { agentes }\end{array}$ & $\begin{array}{l}\text { Função de } \\
\text { utilidade }\end{array}$ \\
\hline $\begin{array}{l}\text { Akkermans } \\
(2001)\end{array}$ & SD com A\&A & $\begin{array}{l}\text { Volume } \\
\text { recebido de } \\
\text { entregas }\end{array}$ & $\begin{array}{l}\text { Heterogêneas } \\
\text { em uma } \\
\text { mesma } \\
\text { simulação }\end{array}$ & $\begin{array}{l}\text { Quantidade de } \\
\text { trocas de } \\
\text { fornecedor }\end{array}$ \\
\hline $\begin{array}{l}\text { Schieritz e } \\
\text { Größler (2003) }\end{array}$ & SD com A\&A & $\begin{array}{l}\text { Volume } \\
\text { recebido e } \\
\text { rapidez de } \\
\text { entregas }\end{array}$ & $\begin{array}{l}\text { Homogêneas, } \\
\text { variando por } \\
\text { simulação }\end{array}$ & $\begin{array}{l}\text { Quantidade de } \\
\text { trocas de } \\
\text { fornecedor }\end{array}$ \\
\hline $\begin{array}{l}\text { Lin, Sung e Lo } \\
\text { (2005) }\end{array}$ & $\begin{array}{l}\text { Modelo } \\
\text { cognitivo } \\
\text { próprio }\end{array}$ & $\begin{array}{l}\text { Preço e tempo } \\
\text { de entrega }\end{array}$ & $\begin{array}{l}\text { Homogêneas, } \\
\text { variando por } \\
\text { simulação }\end{array}$ & $\begin{array}{l}\text { Custo, taxa de } \\
\text { entrega e } \\
\text { tempo de ciclo } \\
\text { da SC }\end{array}$ \\
\hline $\begin{array}{l}\text { Giardini, Tosto } \\
\text { e Conte (2008) }\end{array}$ & $\begin{array}{l}\text { Modelo } \\
\text { cognitivo } \\
\text { próprio }\end{array}$ & $\begin{array}{l}\text { Qualidade } \\
\text { preço) }\end{array}$ & $\begin{array}{l}\text { Homogêneas, } \\
\text { variando por } \\
\text { simulação }\end{array}$ & $\begin{array}{l}\text { Qualidade e } \\
\text { capital } \\
\text { acumulado }\end{array}$ \\
\hline Kim (2009) & $\begin{array}{l}\text { SD com A\&A } \\
\text { e Beer Game }\end{array}$ & $\begin{array}{l}\text { Proporção } \\
\text { entre pares de } \\
\text { pedidos e } \\
\text { entregas }\end{array}$ & $\begin{array}{l}\text { Homogêneas, } \\
\text { variando por } \\
\text { simulação }\end{array}$ & $\begin{array}{l}\text { Flutuação nos } \\
\text { níveis de } \\
\text { estoque }\end{array}$ \\
\hline $\begin{array}{l}\text { Hou et al. } \\
\text { (2014) }\end{array}$ & $\begin{array}{l}\text { Baseado em } \\
\text { modelo } \\
\text { financeiro }\end{array}$ & $\begin{array}{l}\text { entregas } \\
\text { pontuais }\end{array}$ & $\begin{array}{l}\text { Homogêneas, } \\
\text { variando por } \\
\text { simulação }\end{array}$ & $\begin{array}{l}\text { Capital de } \\
\text { trabalho e } \\
\text { firmas ativas }\end{array}$ \\
\hline
\end{tabular}

\subsection{Síntese}

O estado da arte foi delineado neste capítulo para os estudos em meio aos quais esta pesquisa se insere. Na seção 3.1, tais estudos foram enumerados e descritos, subdivididos entre os que usam e os que não usam SD para modelar seus agentes. Após isso, na seção 3.2, estes mesmos estudos foram tabelados e comparados em relação a uma série de critérios. A partir desta comparação, uma lacuna de pesquisa a qual este trabalho pretende preencher foi diagnosticada, descrita a seguir. 


\section{Proposta}

Tendo em vista a lacuna identificada na seção 3.2, esta pesquisa diferencia-se das demais ao buscar medir não apenas a utilidade global na SC, mas também o desempenho individual de agentes com perfis de atuação distintos, à base ou não de confiança, interagindo simultaneamente em uma mesma SC modelada segundo as regras do Beer Game. Para tanto, o modelo utilizado, o fluxo, os perfis e políticas a serem avaliadas, são detalhados a seguir.

\subsection{Modelo de cadeia de suprimentos}

De maneira similar a Kim (2009), a cadeia simulada é composta por 5 níveis: fábricas, distribuidores, atacadistas, revendedores e consumidores finais. Cada nível possui um mesmo número predefinido de agentes. A cada rodada, cada um dos agentes de um nível pode fazer seu pedido a um dos fornecedores presentes no nível superior, assim como deve atender a eventuais pedidos feitos por cada um dos clientes presentes no nível inferior. A Figura 4.1 apresenta um exemplo de possíveis escolhas de fornecedores dos agentes na rodada inicial, em uma cadeia com 3 agentes por nível.

\subsection{Modelo de agente}

Neste trabalho, utilizamos agentes cuja arquitetura é subdividida em:

- Percepção: o agente detecta os carregamentos por seu fornecedor e os pedidos enviados por seus clientes;

- Raciocínio: o agente raciocina e decide a quais clientes enviar os carregamentos (primeiro entregue àqueles a quem deve mais) e dimensiona o pedido para o fornecedor;

- Ação: o agente envia as remessas aos seus clientes e um pedido ao seu fornecedor.

Cada integrante da SC é programado para operar de acordo com as regras do Beer Game (Seção 2.2) e controlar o estoque de acordo com o mecanismo de A\&A (Seção 2.1.3). Os parâmetros para o estado interno e seus valores iniciais inicial são os mesmos presentes em Edali e Yasarcanb (2014), e são listados abaixo: 


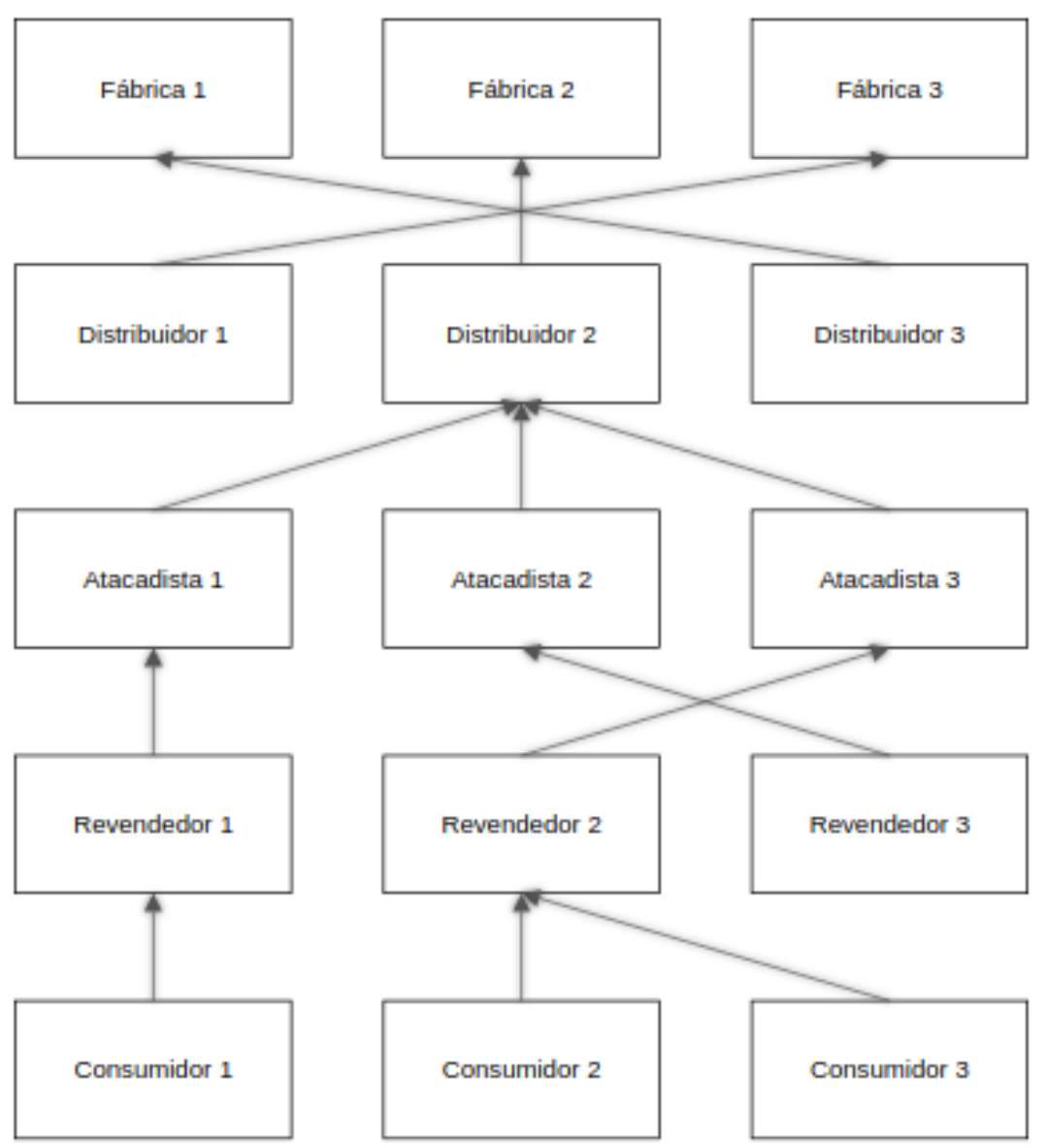

Figura 4.1 - Exemplo de possíveis escolhas de fornecedores de uma SC simulada na rodada inicial

- Atraso dos pedidos: os pedidos dos clientes demoram 1 rodada para chegar a seus fornecedores. Pedidos da fábrica também demoram 1 rodada para serem inseridos em suas próprias linhas de produção;

- Atraso dos carregamentos: os carregamentos dos fornecedores demoram 2 rodadas para chegar a seus clientes. Nas fábricas, os lotes na linha de produção também demoram 2 rodadas para serem produzidos e disponibilizados como estoque em mãos;

- Estoques iniciais: todos os agentes iniciam a simulação com 12.0 unidades de estoque em mãos;

- Pedidos em atraso iniciais: todos os agentes começam sem pedidos em atraso a qualquer cliente, portanto 0.0 para todos;

- Pedidos em trânsito: todos os pedidos em trânsito e ordens de produção são inicializados com 4.0 unidades para cada rodada de atraso (1 rodada); 
- Carregamentos em trânsito: todos os carregamentos em trânsito e linhas de produção são inicializados com 4.0 unidades para cada rodada de atraso (2 rodadas).

Os valores para a demanda de consumidor final e os parâmetros das equações de A\&A (seção 2.1.3) são detalhados no Capítulo 5.

\subsection{Modelo de capital financeiro}

O modelo financeiro proposto é baseado naquele proposto em Hou et al. (2014). Para cada agente, a variação de capital $\Delta C$ após cada rodada é expressa pela equação 4.1 .

$$
\Delta C_{i}(n)=\left(\sum_{k \text { in } K}\left(v_{i}(n)-p\right) * O_{k i}(n)\right)-u * S_{i}(n)-v_{j}(n) * O_{i j}(n)
$$

onde:

- $n$ é a rodada atual,

- $v_{i}(n)$ é o preço unitário de venda fixado por $i$ para a rodada $\mathrm{n}$,

- $p$ é o custo unitário de produção,

- $O_{k i}(n)$ é o tamanho do pedido feito pelo cliente $k$ ao agente $i$ na rodada $\mathrm{n}$,

- $u$ é o custo unitário de armazenamento,

- $S_{i}(n)$ é o estoque em mãos do agente $i$ ao final da rodada $\mathrm{n}$,

- $v_{j}(n)$ é o preço de compra unitário fixado pelo fornecedor $j$ para a rodada $\mathrm{n}$,

- $O_{i j}(n)$ é o tamanho do pedido feito por $i$ ao fornecedor $j$ na rodada $\mathrm{n}$.

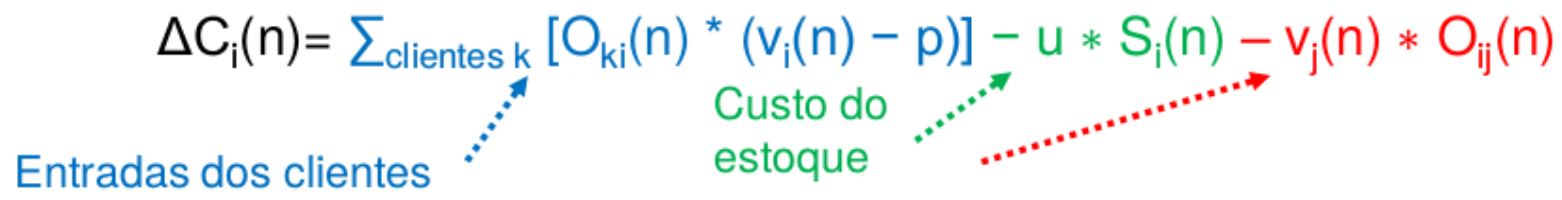

Saída para fornecedor

Figura 4.2 - Parcelas do saldo de capital acumulado

A Figura 4.2 apresenta outra visão da equação 4.1 , destacando as entradas e saídas de capital a cada rodada para um agente $i$ :

- Em azul, as entradas correspondentes às vendas de $i$ para cada cliente $k$; 
- Em verde, a saída correspondente ao custo de manutenção do estoque de $i$;

- Em vermelho, a saída correspondente às compras por $i$ junto ao fornecedor $j$.

Os preços de custo de cada agente correspondem aos preços de venda definidos pelo fornecedor. Esses preços variam a cada intervalo de contrato entre $v_{\min }^{j}$ e $v_{\text {max }}^{j}$, calculados por nível $j$ da SC, da seguinte maneira:

1. O custo por unidade de estoque $u$ por rodada é convencionado $\$ 1$;

2. O custo de produção $p$ é considerado o mesmo para cada nível da cadeia e parametrizado em função de $u$;

3. Para a fábrica, $v_{\min }^{0}$ é igual ao custo de produção $p$ e $v_{\max }^{0}$ é igual a $v_{\min }^{0}+p$;

4. Para cada nível abaixo, $v_{\min }^{j}$ é igual a $v_{\max }^{j-1}+p$ e $v_{\max }^{j}$ é igual a $v_{\min }^{j}+p$.

\subsection{Modelo de confiança}

Para quantificar o nível de confiança de um cliente em seu fornecedor, utiliza-se o cálculo proposto por Hou et al. (2014). A cada rodada, o nível de confiança é dado pela proporção histórica entre os carregamentos entregues a cada rodada e os pedidos correspondentes feitos três rodadas antes. Tal defasagem compreende a soma dos tempos de transmissão de pedido ao fornecedor e de envio de carregamentos por esta ao seu cliente, conforme mencionado na seção 2.2. Esta proporção é expressa pela equação 4.2 .

$$
\operatorname{Trust}_{i j}(n)=\sum_{r=4}^{n} S_{j i}(r) / \sum_{r=1}^{n-3} O_{i j}(r)
$$

onde:

- $n$ é a rodada atual,

- $O_{i j}(r)$ é o pedido enviado por $i$ ao fornecedor $j$ na rodada $r$,

- $S_{j i}(r)$ é o carregamento que $i$ recebeu de $j$ na rodada $r$,

- Trust $_{i j}(n)$ é a confiança de $i$ em $j$ na rodada $n$. 


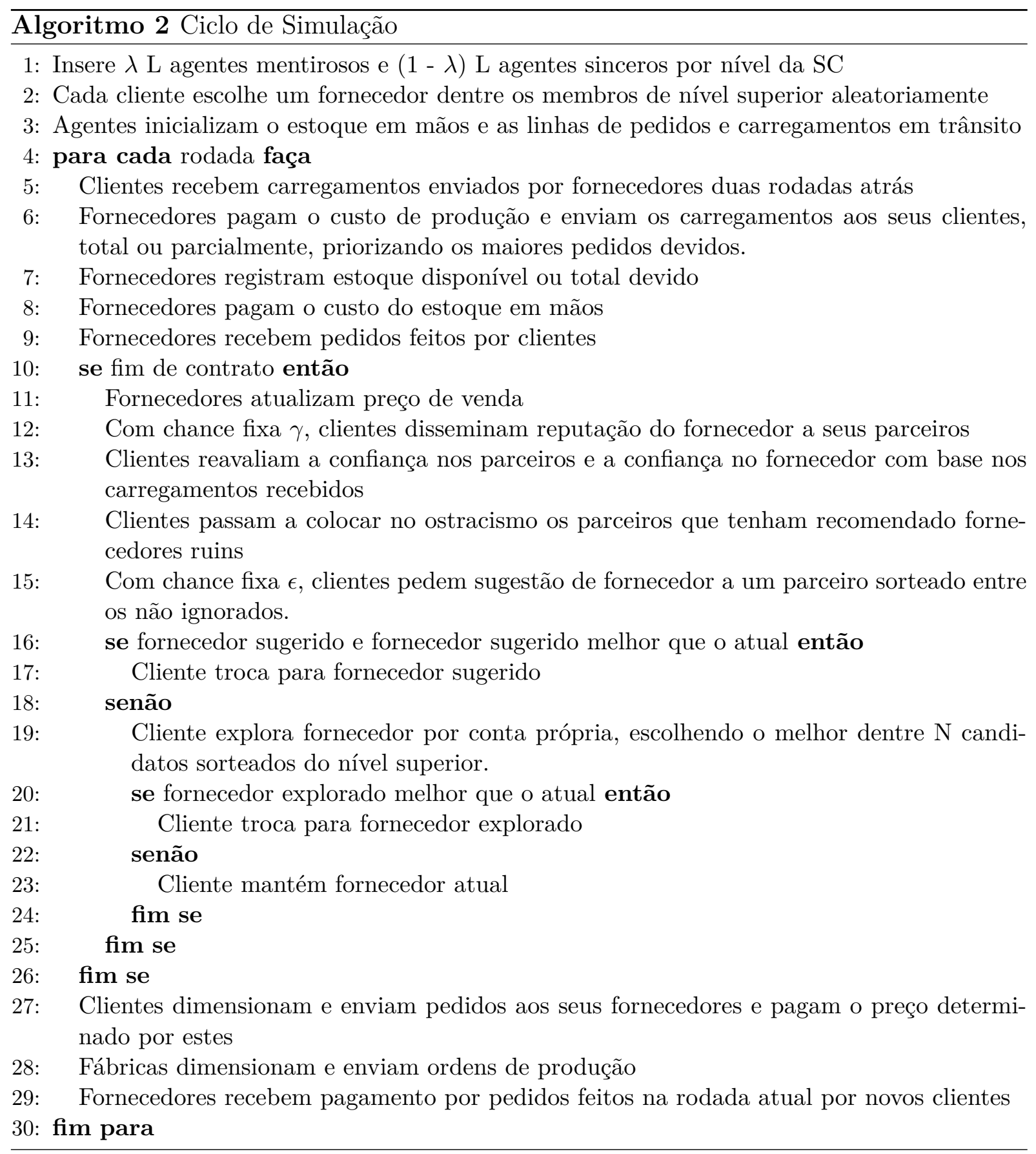




\subsection{Ciclo de simulação}

O ciclo de simulação, apresentado no Algoritmo 2 proposto consiste em uma extensão do algoritmo 1 original do Beer Game (seção 2.2).

Neste algoritmo, existem três parâmetros importantes:

- $\lambda$ : representa a proporção de agentes mentirosos na população, utilizado na linha 1;

- $\gamma$ : representa a taxa de disseminação de reputação na população, utilizado na linha 12;

- $\epsilon$ : representa a chance de um agente solicitar a um informante informações sobre fornecedores, utilizado na linha 15;

Um exemplo de execução de um ciclo de simulação deste algoritmo é apresentado na Seção 4.10. Entretanto, para melhor compreensão deste exemplo, como um dos objetivos deste trabalho é possibilitar a simulação de SC cujos agentes tenham perfis de atuação distintos, cabe discutí-los anteriormente.

\subsection{Perfis de agentes}

Cada nível da SC será composto por agentes pertencentes a um determinado perfil. Neste trabalho, dois perfis distintos são propostos, cada um deles norteado por um objetivo que incorre em uma combinação de políticas de decisão.

\subsubsection{Agentes populares}

Um agente popular visa atrair o maior número possível de clientes por meio de preço baixo, e mantê-los por meio da entrega o mais pontual possível dos pedidos feitos a ele.

\subsubsection{Agentes gananciosos}

Um agente ganancioso tem por objetivo maximizar o seu capital acumulado comprando barato, vendendo caro e reduzindo despesas.

\subsection{Políticas de decisão}

O ciclo de simulação, apresentado na Seção 4.5, indica que os agentes devem realizar várias escolhas durante o ciclo de simulação: (i) qual fornecedor deve utilizar, qual o tamanho do seu estoque, qual o preço de seu produto. Todas estas escolhas 
estão condicionadas ao perfil do agente em questão, e fazem parte do ciclo de ações executado a cada rodada.

\subsubsection{Escolha de fornecedor}

A decisão de manter o fornecedor atual ou mudar para um novo fornecedor é feita levando em conta características distintas dos fornecedores disponíveis. A cada $d$ rodadas, onde $d$ é um inteiro parametrizado, a janela de mudança é acionada: todos os clientes reavaliam a confiança em seus respectivos fornecedores, para então aplicar o algoritmo de decisão previsto em seu próprio perfil.

- Popular - um agente com perfil popular privilegia fornecedores em que possui maior confiança, uma vez que atrasos em entregas de pedidos provocam escassez no estoque do agente em questão, o que pode inviabilizar as entregas a seus clientes. O Algoritmo 3 detalha como se dá esta escolha.

\footnotetext{
Algoritmo 3 Procedimento para escolha do fornecedor

1: Com $\epsilon$ chance, onde $\epsilon$ é a taxa de disseminação, o agente seleciona um parceiro aleatório entre os que ele confia, e pede a ele sugestões de fornecedores

2: O parceiro escolhido, se for sincero, informa todos os fornecedores bons com os quais interagiu até agora, cuja taxa de confiança excede o limite de 0,5

3: O agente então toma o fornecedor com a maior taxa informada e compara ao seu fornecedor atual. Se a primeira taxa for maior que a segunda, o agente muda para o novo fornecedor. Caso contrário, prossegue ao próximo passo, a exploração

4: $\mathrm{O}$ agente sorteia um conjunto de $\mathrm{N}$ candidatos a fornecedor bons e escolhe, entre os $\mathrm{N}$ sorteados, aquele em que mais confia

5: Se o fornecedor escolhido tiver um nível de confiança maior que o atual, o agente muda do atual para o escolhido. Caso contrário, mantém o atual
}

- Ganancioso - Um agente com perfil ganancioso privilegia fornecedores mais baratos. O algoritmo utilizado é análogo ao do agente popular, exceto que o critério de decisão utilizado nos passos 3 e 5 é o preço mais barato, ao invés da maior taxa de confiança.

\subsubsection{Gerenciamento de estoque}

Esta escolha diz respeito ao dimensionamento do estoque de segurança, mencionado na seção 5.2. A decisão de manter ou não este estoque depende do perfil do agente. 
- Popular Um agente popular tem como estoque desejado $\mathrm{S}^{*}$ o estoque de confiança parametrizado, a fim de prevenir-se contra picos de demanda que prejudiquem suas entregas.

- Ganancioso Um agente ganancioso não mantém estoque de segurança $\left(\mathrm{S}^{*}=\right.$ 0), de forma a reduzir o custo de manutenção de seu estoque.

\subsubsection{Controle de preço}

Tal divisão refere-se à estratégia do agente para fixação, a cada rodada, do preço a ser praticado, logo antes da procura dos seus produtos por clientes em potencial.

- Popular Um agente popular mantém o preço baixo, a fim de atrair clientes focados em preço baixo. Em cada rodada, define aleatoriamente o preço entre $v_{\min }$ e $v_{\max }-\delta *\left(v_{\max }-v_{\min }\right)$, obtido de uma distribuição uniforme.

- Ganancioso Um agente ganancioso mantém o preço alto, de modo a maximizar sua margem de lucro. Em cada rodada, define aleatoriamente o preço entre $v_{\min }+\delta *\left(v_{\max }-v_{\min }\right)$ e $v_{\max }$, obtido de uma distribuição uniforme.

\subsubsection{Síntese}

As diferenças entre os agentes populares e os agentes gananciosos, em termos das várias políticas de decisão, são resumidas na Tabela 4.1.

Tabela 4.1 - Síntese das políticas de decisão

\begin{tabular}{|l|l|l|}
\hline & Popular & Ganancioso \\
\hline Escolha de fornecedor & Maior confiança & Menor preço \\
\hline Gerenciamento de estoque & Estoque de segurança $S^{*}$ & Sem estoque de segurança \\
\hline Controle de preço & $\begin{array}{l}\text { Entre } v_{\min } \text { e } v_{\max }-\delta * \\
\left(v_{\max }-v_{\min }\right)\end{array}$ & $\begin{array}{l}\text { Entre } v_{\min }+\delta *\left(v_{\max }-v_{\min }\right) \\
\text { e } v_{\max }\end{array}$ \\
\hline
\end{tabular}

\subsection{Mecanismo de reputação}

Como mencionado no início deste capítulo, um diferencial deste trabalho é permitir uma reconfiguração da SC por meio da confiança que os agentes têm uns nos outros. Um modo de obter tal medida, como discutido na Seção 2.3.2, é através de um mecanismo de reputação.

Assim, estabeleceu-se em nossa abordagem que ao final de um contrato, um cliente, com chance $\gamma$, dissemina reputação sobre o fornecedor contratado, conforme 
consta no Algoritmo 2, linha 11. Considerando a equação 4.2, a reputação age, para cada outro agente no nível do cliente, da seguinte forma:

1. Ao histórico de pedidos $P_{i}$ a receber do fornecedor pelo agente informado em cada rodada i desde o início da simulação, são incorporados os pedidos $P_{j}$ a receber do fornecedor pelo agente informante desde o início do contrato recémfinalizado;

2. Ao histórico de carregamentos $C_{i}$ recebidos pontualmente do fornecedor pelo agente informado em cada rodada i desde o início da simulação, são incorporados os carregamentos $C_{j}$ recebidos pontualmente do fornecedor pelo agente informante em cada rodada j desde o início do contrato recém-finalizado;

3. A confiança de cada agente informado no fornecedor é recalculada dividindo-se a soma do item anterior pela soma do primeiro item.

\subsection{Agentes sinceros e mentirosos}

Outro objetivo deste trabalho, mencionado na Seção 1.2, é avaliar o efeito da presença de agentes mentirosos no capital acumulado e na pontualidade de entrega dos agentes de uma SC.

Assim, no início de cada simulação, uma parcela fixa $\lambda$ de agentes por nível da SC são programados como mentirosos. Quando perguntado por sugestões, um mentiroso só retorna maus fornecedores. Para mascarar esta sugestão ao parceiro que lhe pergunta, o agente mentiroso transmite cada fornecedor como se fosse bom, com confiança igual (1 - confiança real) e preço igual a $\left(v_{\min }+v_{\max }\right.$ - preço real). Quando dissemina reputações, um agente mentiroso, em vez de incorporar os carregamentos $C_{j}$ recebidos pontualmente em cada rodada $j$ ao histórico dos agentes informados, incorpora a soma de $P_{j}-C_{j}$, ou seja, os carregamentos não recebidos a tempo, como tivessem sido recebidos pontualmente.

Ao final de um contrato, um cliente registra o preço e a taxa de confiança acumulada do fornecedor contratado. Caso esta taxa seja baixa, o fornecedor é considerado ruim. Adicionalmente, se tal fornecedor tenha sido sugerido por um parceiro, este último é marcado pelo cliente como sendo não confiável; neste caso, o cliente não Ihe enviará mais pedidos de sugestões e tampouco lhe enviará sugestões caso seja indagado.

A atribuição de um rótulo ruim para um fornecedor depende do perfil do agente. Para agentes populares, são aqueles cuja taxa de confiança seja inferior a 0,5. Já 
para os agentes gananciosos, são aqueles cujo preço se encontre na metade superior do intervalo do nível da SC.

Já no caso das reputações, não é possível colocar no ostracismo informantes não confiáveis, uma vez que, pela definição de reputação (Seção 2.3), este é um fenômeno impessoal em que o disseminador não pode ser identificado.

\subsection{Exemplo de ciclo de simulação}

Considerando-se a SC da Figura 4.1, composta por 3 agentes por nível, apresenta-se a seguir um exemplo de execução de um ciclo de simulação definido no Algoritmo 2, com foco no Revendedor 1. Para efeito explicativo, supõe-se neste exemplo que $100 \%$ dos agentes tenham o perfil popular.

1. Supondo uma taxa de mentirosos $\lambda=1 / 3$, em cada nível da SC são inseridos 2 agentes populares sinceros (agentes 1 e 2 ) e 1 popular mentiroso (agente 3 ).

2. O Consumidor 1 sorteia o Revendedor 1 como sendo o seu fornecedor, e este, por sua vez, sorteia o Atacadista 1 para a mesma função. Os Consumidores $2 e$ 3 sorteiam o Revendedor 2.

3. Cada agente inicia o ciclo com $\$ 0$ de saldo, 12 unidades de estoque em mãos, um pedido em trânsito de 4 unidades que demanda 1 rodada para chegar do cliente, um pedido em mãos de 4 unidades a ser atendido de imediato, e ainda mais dois grupos de carregamentos em trânsito, de 4 unidades cada, um deles demandando 1 rodada e o outro 2 rodadas para chegar de seus fornecedores. Uma exceção é feita para o Consumidor 3 , cujo carregamento a 1 rodada de chegar do Revendedor 2 é inicializado com apenas 1 unidade.

4. A primeira rodada é iniciada.

5. O Revendedor 1 recebe o primeiro carregamento de 4 unidades vindo do Atacadista 1, e o Consumidor 1 recebe o primeiro carregamento de 4 unidades vindo do Revendedor 1. O Consumidor 3 recebe 1 unidade do Revendedor 2.

6. Supondo um custo de produção $p=\$ 10$ por unidade, o Revendedor 1 paga $\$ 40$ para atender o pedido em mãos do Consumidor 1, enviando-Ihe um carregamento de 4 unidades, ficando com saldo negativo de $\$ 40$. O Atacadista 1 faz o mesmo com relação ao pedido em mãos do Revendedor 1 .

7. O Revendedor 1 registra 12 unidades de estoque em mãos. 
8. Supondo um custo de manutenção $u=\$ 1$ por unidade por rodada, o Revendedor 1 paga $\$ 12$ pelo seu estoque em mãos, ficando com saldo negativo de $\$ 52$.

9. O pedido em trânsito de 4 unidades do Consumidor 1 chega ao Revendedor 1.

10. Supondo duração de contrato $d=1$ para efeito ilustrativo, todos os contratos são encerrados logo na primeira rodada e a janela de mudança de fornecedor é acionada.

11. Com $p=\$ 10$, os intervalos de preços possíveis são entre $\$ 10$ e $\$ 20$ para fábricas, entre $\$ 30$ e $\$ 40$ para distribuidores, entre $\$ 50$ e $\$ 60$ para atacadistas e entre $\$ 70$ e $\$ 80$ para revendedores. Supondo um valor do parâmetro de controle de preço $\delta=0,25$, tem-se que os agentes populares sorteiam seu preço na faixa de valores entre $v_{\min }$ e $v_{\max }-\delta *\left(v_{\max }-v_{\min }\right)$, conforme indicado na Tabela 4.1. Assim, nesta janela, suponha que o Atacadista 1 sorteie o valor \$55 (no intervalo entre $\$ 50$ e $\$ 57,5$ ), e o Revendedor 1 sorteie o valor $\$ 72$ (no intervalo $\$ 70$ a $\$ 77,5)$ como sendo os preços por unidade fornecida ofertados no mercado.

12. Supondo um valor de chance de disseminação de reputação $\gamma=0,3$, e aplicando essa chance a todos os agentes, imagine-se que por acaso Revendedor 1 não dissemine a reputação do Atacadista 1 para os demais revendedores, mas que o Consumidor 1 o faça, enviando uma reputação sincera do Revendedor 1 para os demais consumidores: ele reporta que recebeu deste revendedor 4 unidades, dentre as 4 que havia pedido, durante o contrato de 1 rodada de duração.

13. O Revendedor 1 recalcula então a pontualidade do seu fornecedor (Atacadista 1) como sendo $100 \%$, levando em conta as 4 unidades recebidas de um total de 4 unidades pedidas. O Consumidor 1 calcula o mesmo valor em relação ao seu fornecedor (Revendedor 1). Os Consumidores 2 e 3, apesar de não terem interagido com o Revendedor 1 , levam em conta a reputação disseminada sobre este revendedor pelo Consumidor 1 no passo anterior e adotam o mesmo valor. Por fim, o Consumidor 3, tendo recebido apenas 1 unidade das 4 unidades pedidas ao Revendedor 2, calcula que este teve uma pontualidade de $25 \%$.

14. Adotando um valor de chance de pedido de sugestão de fornecedores $\epsilon=0,4$, suponha-se que por acaso o Revendedor 1 não tenha solicitado sugestão a ninguém, mas que o Consumidor 1 o tenha feito ao Consumidor 3 , de perfil mentiroso. Apesar da taxa de pontualidade do Revendedor 2 ter sido de $25 \%$, este 0 recomenda ao Consumidor 1 com pontualidade $(1-0.25)=75 \%$. 
15. O Consumidor 1 constata então que o seu fornecedor (Revendedor 1 ) tem $100 \%$ de pontualidade, e portanto é mais confiável que o Revendedor 2, com $75 \%$, e ignora a sugestão proveniente do Consumidor 3.

16. Adotando um valor de $\mathrm{N}=1$ fornecedores explorados ao acaso, suponha que o Consumidor 3 tenha encontrado o Revendedor 1 durante a busca. A taxa de pontualidade do Revendedor 1 é $100 \%$ para o Consumidor 3, efeito da reputação disseminada pelo Consumidor 1 , e maior do que os $25 \%$ de taxa de pontualidade do Revendedor 2, seu último fornecedor. Assim, o Consumidor 3 decide trocar de fornecedor, do Revendedor 2 para o Revendedor 1. Por outro lado, tanto o Revendedor 1 quanto o Consumidor 1 mantém seus fornecedores 100\% confiáveis. Assim, a janela de troca de fornecedores é fechada.

17. Tanto o Consumidor 1 quanto o Consumidor 3 fazem novos pedidos de 4 unidades, e inserem os pedidos na fila do Revendedor 1 , descontando 4 * $\$ 72=$ $\$ 288$ dos respectivos saldos. O Revendedor 1 então calcula seu pedido para - Atacadista 1 com base nas equações apresentadas na seção 2.1.3, visando manter $S^{*}=12$ unidades de estoque de segurança, $S L^{*}=12$ unidades na linha de suprimento, com $\alpha_{s}=0,5 ; \alpha_{s L}=0,5$ e $\theta=0,5$. O pedido inserido na fila do Atacadista 1 é de 4 unidades, resultando num pagamento de 4 * $\$ 55=\$ 220$, que é descontado do Revendedor 1 , que fica com saldo negativo de $\$ 52+\$ 220$ $=\$ 272$.

18. O Revendedor 1 recebe, então, os dois pagamentos feitos pelos Consumidores 1 e 3, ficando com saldo positivo de $2{ }^{*} \$ 288-\$ 272=\$ 304$.

19. O algoritmo então retorna ao passo 4, para iniciar a segunda rodada, e repete este ciclo para todas as rodadas.

Após este ciclo de interação, as novas escolhas de fornecedores seriam aquelas respresentadas na Figure 4.3.

Tal exemplo ilustra o efeito da disseminação da reputação, da exploração de fornecedores alternativos e do possível perfil mentiroso dos agentes nos resultados obtidos pelos agentes em um ciclo de simulação correpsondente ao término do contrato (passo 10 do Algoritmo 2). 


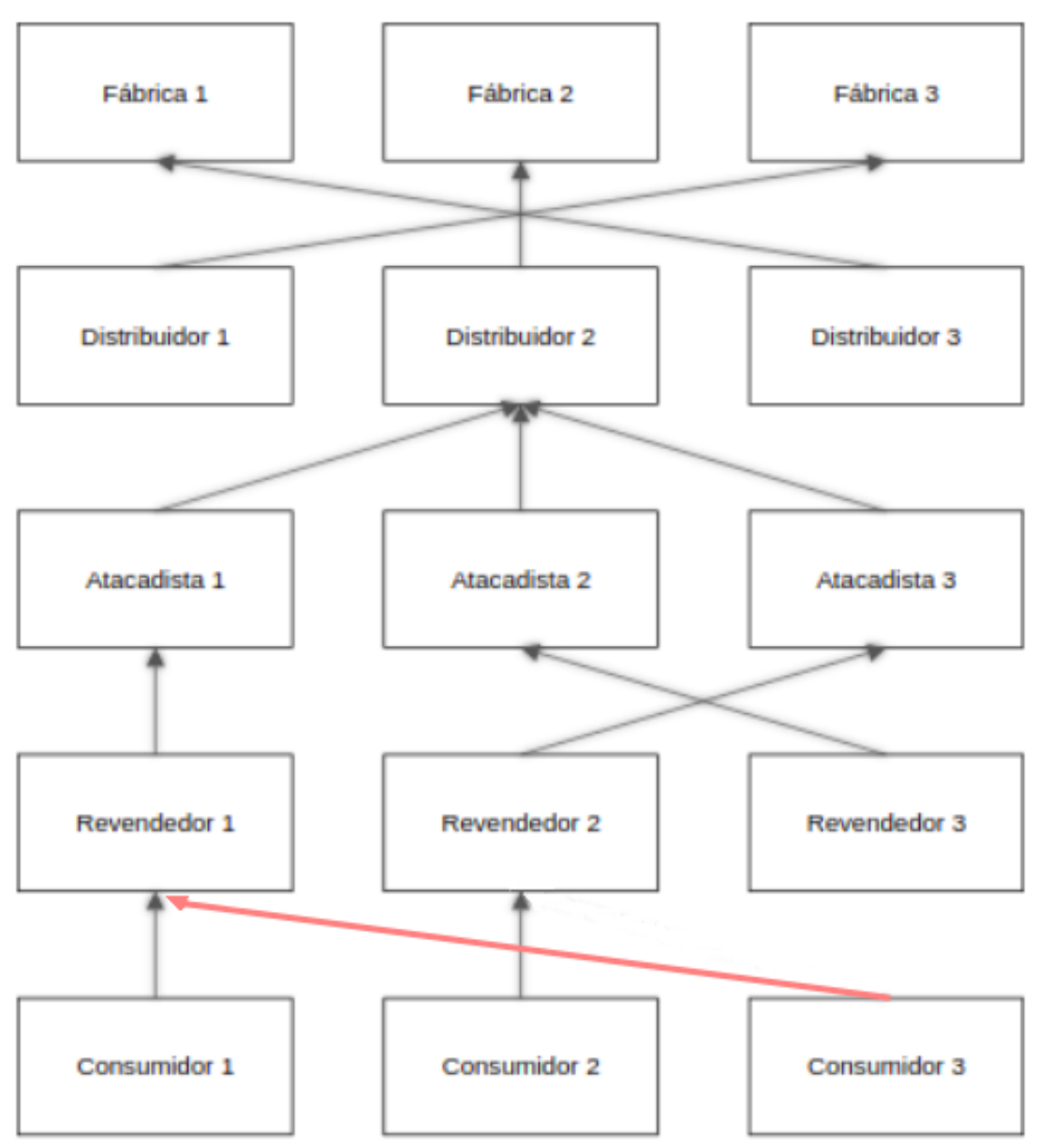

Figura 4.1 - Exemplo de SC simulada

Figura 4.3 - Novas escolhas de uma SC simulada, após troca de fornecedores

\subsection{Síntese}

Neste capítulo, os elementos constituintes do modelo de SC foram descritos formalmente. Primeiramente, a topologia da SC foi detalhada na Seção 4.1, com seus cinco níveis de agentes e um mesmo número de agentes por nível. Em seguida, na Seção 4.2, o modelo dos agentes da SC foi explicitado. O modelo de capital financeiro foi equacionado na seção 4.3, considerando os fluxos de compra, venda e manutenção de estoque. A seção 4.4 introduziu o modelo de confiança, equacionado como a média histórica das entregas pontuais do fornecedor ao cliente, para cada parceria na SC. A Seção 4.5 apresentou o ciclo de simulação. Os perfis de agentes simulados, populares e gananciosos, bem como seus respectivos objetivos estratégicos foram então detalhados na Seção 4.6, e suas políticas de decisão referentes à escolha de fornecedor, gerenciamento de estoques e controle de preços foram discutidas na Seção 4.7. Após isso, o mecanismo de reputação e a atuação de agentes mentirosos, bem como 
seu ostracismo por parte dos agentes que com eles interagem, foram apresentados respectivamente nas Seções 4.8 e 4.9. Por fim, um exemplo de ciclo de simulação foi apresentado na seção 4.10 para ilustrar a execução do algoritmo.

A seguir, serão apresentados detalhes da implementação do modelo, bem como analisados os resultados dos experimentos de simulação, visando responder as perguntas de pesquisa enunciadas na Seção 1.2. 


\section{Implementação e Resultados}

Neste capítulo, são detalhados o ambiente de simulação, os parâmetros e valores adotados no trabalho. São também descritos os experimentos realizados e a análise dos resultados obtidos.

\subsection{Ambiente de simulação}

O projeto foi implementado no ambiente ReLogo (OZIK et al., 2013), uma linguagem de domínio específica (DSL) ${ }^{1}$ para MABS, cuja interface gráfica é exibida na Figura 5.1. Esta ferramenta incorpora as bibliotecas e recursos do framework Repast Simphony (COLLIER, 2003). Além disso, foi programado e executado a partir da IDE Eclipse (ECLIPSE, 2007). Este ambiente foi escolhido devido à familiaridade do autor com a linguagem e também pelo fato do Repast dispor de um simulador com ferramentas úteis e intuitivas, a exemplo dos geradores de gráficos e das tabelas de estados atualizadas a cada passo para depuração.

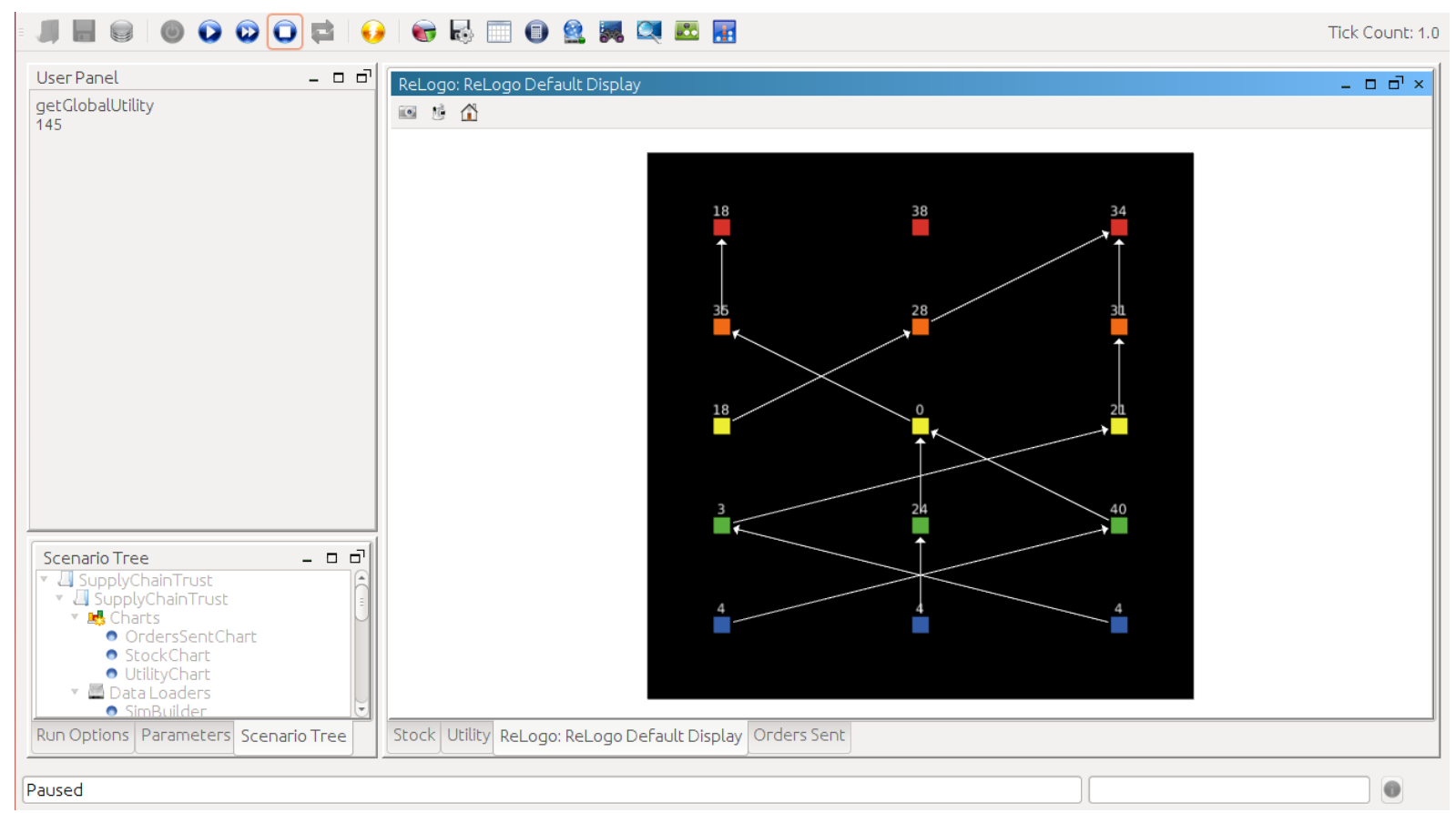

Figura 5.1 - Interface gráfica para o simulador ReLogo

1 Do inglês domain specific language. 


\subsection{Parâmetros de entrada}

Para os experimentos deste artigo, a população dos agentes do SC foi dividida considerando $50 \%$ dos agentes com perfil popular e 50\% com perfil ganancioso, a fim de determinar qual estratégia prevalece sobre a outra se ambas forem adotados pelo mesmo número de agentes.

Outro parâmetro necessário é a demanda dos consumidores finais, que obedece ao padrão descrito na seção 2.2: cada consumidor solicita ao respectivo fornecedor 4 unidades por rodada até a quarta rodada, e 8 unidades por rodada a partir da quinta rodada em diante.

Os demais parâmetros foram definidos empiricamente a partir de execuções da simulação ou utilizando os valores adotados por Edali e Yasarcanb (2014), como mostrado na Tabela 5.1.

Tabela 5.1 - Parâmetros de entrada

\begin{tabular}{|c|c|c|}
\hline Parâmetro & Descrição & Valores \\
\hline $\mathrm{D}$ & $\begin{array}{l}\text { Duração da simulação em } \\
\text { passos }\end{array}$ & 200 \\
\hline $\mathrm{d}$ & $\begin{array}{l}\text { Duração dos contratos de } \\
\text { fornecimento em passos - } \\
\text { seção } 4.7 .1\end{array}$ & 10 \\
\hline $\mathrm{L}$ & Agentes por nível da SC & 20 \\
\hline $\mathrm{S}^{*}$ & $\begin{array}{l}\text { Estoque desejado - (eq. } \\
2.3)\end{array}$ & 24 \\
\hline $\mathrm{p}$ & $\begin{array}{l}\text { Custo de produção - seção } \\
4.3\end{array}$ & 10 \\
\hline$\alpha_{s}$ & $\begin{array}{l}\text { Parâmetro para ajuste de } \\
\text { estoque - eq. } 2.3 \text { ) }\end{array}$ & 0,5 \\
\hline$\beta$ & $\begin{array}{l}\alpha_{s L} / \alpha_{s} \text { - parâmetro para } \\
\text { ajuste da linha de supri- } \\
\text { mentos - eqs. } 2.3 \text { e } 2.4\end{array}$ & 1,0 \\
\hline$\Theta$ & $\begin{array}{l}\text { Parâmetro para previsão de } \\
\text { demanda - eq. } 2.2\end{array}$ & 0,5 \\
\hline $\mathrm{N}$ & $\begin{array}{l}\text { Parâmetro para escolha de } \\
\text { fornecedor - seção } 4.7 .1\end{array}$ & 5 \\
\hline$\delta$ & $\begin{array}{l}\text { Diferencia preços entre per- } \\
\text { fis - seção } 4.6\end{array}$ & 0,25 \\
\hline
\end{tabular}




\subsection{Descrição dos experimentos}

Inicialmente, foi realizada uma simulação com o formato original do Beer Game, isto é, com $D=36, L=1, N=1, S^{*}=12$, e demais parâmetros conforme a Tabela 5.1. Os resultados foram similares aos obtidos por Edali e Yasarcanb (2014), o que indicou a validação do algoritmo implementado.

A seguir, os experimentos descritos na Tabela 5.2 foram realizados para responder às perguntas de pesquisa formuladas na seção 1.2, projetados de forma a poder avaliar o impacto das sugestões e reputações, tanto em cenários formados apenas por agentes sinceros quanto em outros em que há agentes mentirosos.

Nesta tabela, existem três parâmetros importantes:

- $\epsilon$ : representa a chance de um agente solicitar a um informante informações sobre fornecedores, onde $\epsilon \in[0,0 ; 1,0]$;

- $\lambda$ : representa a proporção de agentes mentirosos na população, onde $\lambda \in$ $[0,0 ; 1,0]$;

- $\gamma$ : representa a a taxa de disseminação de reputação na população, onde $\gamma \in$ $[0,0 ; 1,0]$;

Tabela 5.2 - Lista de experimentos e parâmetros associados

\begin{tabular}{|l|c|c|}
\hline Experimento & Perguntas & Parâmetros \\
\hline 1 - Efeito de sugestões sinceras & 1,2 & $\epsilon \in\{0,0 ; 0,1 ; \ldots ; 0,9 ; 1,0\}$ \\
\hline 2 - Efeito de sugestões mentirosas & 3 & $\begin{array}{c}\lambda \in\{0,0 ; 0,25 ; 0,5 ; 0,75 ; 1,0\} \\
\epsilon \in\{0,25 ; 0,5 ; 0,75 ; 1,0\}\end{array}$ \\
\hline 3 - Efeito de reputações sinceras & 4 & $\gamma \in\{0,0 ; 0,1 ; \ldots ; 0,9 ; 1,0\}$ \\
\hline 4 - Efeito de reputações mentirosas & 4 & $\begin{array}{c}\lambda \in\{0,0 ; 0,25 ; 0,5 ; 0,75 ; 1,0\} \\
\gamma \in\{0,25 ; 0,5 ; 0,75 ; 1,0\}\end{array}$ \\
\hline
\end{tabular}

\subsection{Resultados obtidos}

Na sequência, apresentam-se os resultados obtidos em cada um dos quatro experimentos, incluindo média $(\mu)$, desvio padrão $(\sigma)$ e coeficiente de variação $(C V=\sigma / \mu)$. Resultados preliminares, e não completos, destes experimentos foram apresentados em (JALBUT; SICHMAN, 2018a). 


\subsubsection{Experimento 1 - efeito de sugestões sinceras}

Neste experimento, todos os agentes foram programados para dizer a verdade $(\lambda=0)$, e foram submetidos a diferentes taxas de sugestões ( $\epsilon$ variando de 0,0 a 1,0 com 0,1 incremento). Cada cenário foi executado 20 vezes, com resultados para cada perfil mapeado nas Tabelas 5.3 (capital acumulado) e 5.4 (pontualidade).

Tabela 5.3 - Capital acumulado por taxa de sugestões $\epsilon$

\begin{tabular}{|l|l|l|l|l|l|l|l|l|l|l|l|l|}
\hline Perfil & $\epsilon$ & 0.0 & 0.1 & 0.2 & 0.3 & 0.4 & 0.5 & 0.6 & 0.7 & 0.8 & 0.9 & 1.0 \\
\hline \multirow{3}{*}{ Popular } & $\mu$ & 103911 & 132337 & 149281 & 155100 & 161794 & 166201 & 166382 & 165265 & 167455 & 169131 & 169787 \\
\cline { 2 - 13 } & $\sigma$ & 20368 & 22343 & 22224 & 15982 & 16099 & 17634 & 14583 & 14581 & 14125 & 14273 & 13165 \\
\cline { 2 - 13 } & $\mathrm{CV}$ & 0.196 & 0.169 & 0.149 & 0.103 & 0.100 & 0.106 & 0.088 & 0.088 & 0.084 & 0.084 & 0.078 \\
\hline \multirow{3}{*}{ Ganancioso } & $\mu$ & 118402 & 86345 & 68881 & 60147 & 51985 & 45621 & 47564 & 46561 & 42655 & 40922 & 40755 \\
\cline { 2 - 12 } & $\sigma$ & 18555 & 23416 & 22528 & 15171 & 14197 & 16568 & 14232 & 14068 & 13149 & 10973 & 11809 \\
\cline { 2 - 12 } & $\mathrm{CV}$ & 0.157 & 0.271 & 0.327 & 0.252 & 0.273 & 0.363 & 0.299 & 0.302 & 0.308 & 0.268 & 0.290 \\
\hline
\end{tabular}

É possível observar que, sem sugestões dos pares $(\epsilon=0)$, agentes gananciosos acumulam mais capital que agentes populares; além disto, com o aumento de $\epsilon$, o capital acumulado pelos populares cresce, enquanto que o acumulado pelos gananciosos decresce.

Tabela 5.4 - Pontualidade por taxa de sugestões $\epsilon$

\begin{tabular}{|l|l|l|l|l|l|l|l|l|l|l|l|l|}
\hline Perfil & $\epsilon$ & 0.0 & 0.1 & 0.2 & 0.3 & 0.4 & 0.5 & 0.6 & 0.7 & 0.8 & 0.9 & 1.0 \\
\hline \multirow{3}{*}{ Popular } & $\mu$ & 0.763 & 0.754 & 0.741 & 0.727 & 0.721 & 0.692 & 0.693 & 0.672 & 0.673 & 0.654 & 0.650 \\
\cline { 2 - 12 } & $\sigma$ & 0.021 & 0.028 & 0.031 & 0.032 & 0.023 & 0.031 & 0.035 & 0.038 & 0.042 & 0.032 & 0.038 \\
\cline { 2 - 12 } & $\mathrm{CV}$ & 0.028 & 0.037 & 0.042 & 0.044 & 0.032 & 0.045 & 0.051 & 0.057 & 0.062 & 0.049 & 0.058 \\
\hline \multirow{3}{*}{ Ganancioso } & $\mu$ & 0.509 & 0.500 & 0.474 & 0.468 & 0.466 & 0.422 & 0.430 & 0.422 & 0.417 & 0.391 & 0.382 \\
\cline { 2 - 12 } & $\sigma$ & 0.052 & 0.046 & 0.048 & 0.045 & 0.039 & 0.037 & 0.034 & 0.047 & 0.059 & 0.035 & 0.031 \\
\cline { 2 - 12 } & $\mathrm{CV}$ & 0.102 & 0.092 & 0.101 & 0.096 & 0.084 & 0.088 & 0.079 & 0.111 & 0.141 & 0.090 & 0.081 \\
\hline
\end{tabular}

Neste experimento, a taxa de pontualidade dos agentes populares é sempre maior que a dos gananciosos, mas, para ambos os perfis, a taxa diminui com o aumento de $\epsilon$. 
Figura 5.2 - Diferença entre taxas de sugestões baixa e alta

(a) $\epsilon=0$

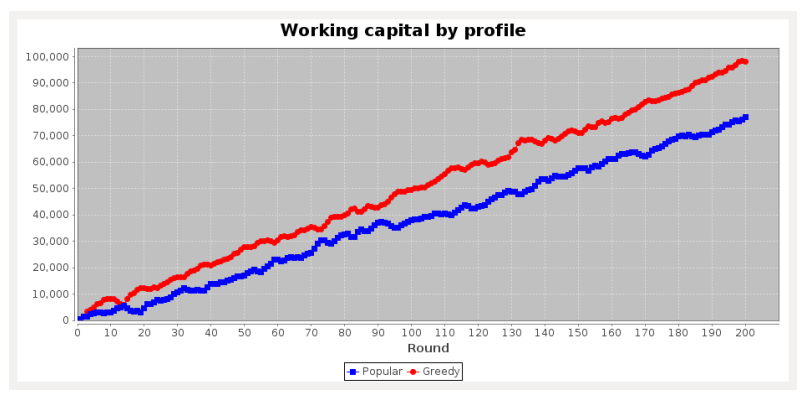

(b) $\epsilon=1$

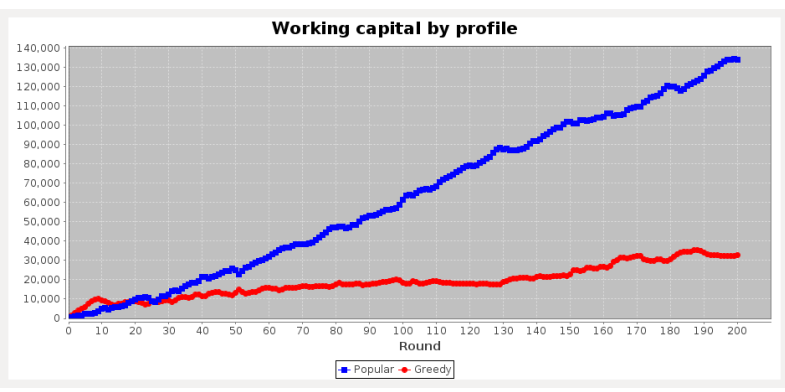

A Figura 5.2 ilustra a diferença entre capital acumulado entre agentes populares e gananciosos em dois diferentes simulações individuais. Quando não há sugestões ( $\epsilon$ $=0$ ), agentes gananciosos (linha vermelha) lucram mais que agentes populares (linha azul). Por outro lado, com $100 \%$ de sugestões $(\epsilon=1)$ agentes gananciosos começam melhor, mas são rapidamente superados por populares.

\section{Figura 5.3 - Tamanho médio dos pedidos por nível da SC por rodada}

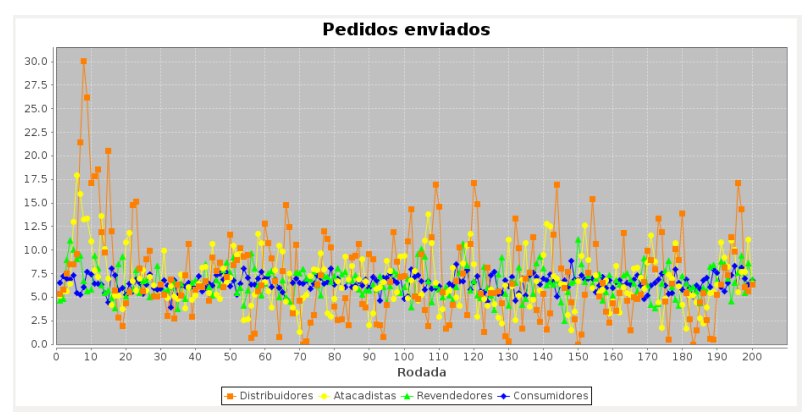

A Figura 5.3, por sua vez, demonstra a ocorrência do BWE em um exemplo de simulação, com a variação da magnitude dos pedidos feitos ao longo da SC. Os pedidos feitos pelo consumidor final aos revendedores (linha azul) são em média menores que os pedidos destes para os atacadistas (linha verde), que são menores que os destes para os distribuidores (linha amarela), que são menores que destes para as fábricas (linha laranja).

\subsubsection{Experimento 2 - efeito de sugestões mentirosas}

Neste experimento, 5 taxas diferentes de mentirosos foram testadas ( $\lambda$ variando de 0,0 a 1,0 com incremento de 0,25 ), combinado com 4 taxas de sugestões ( $\epsilon$ com valores $0,25,0,5,0,75$ e 1,0), para um total de 20 cenários. Mais uma vez, cada cenário foi executado 20 vezes, cujos resultados são mostrados na Tabela 5.5 . 
Tabela 5.5 - Experimento 2

(a) Capital acumulado por taxa de mentirosos $\lambda$

\begin{tabular}{|c|c|c|c|c|c|c|c|}
\hline$\epsilon$ & Perfil & $\lambda$ & 0.00 & 0.25 & 0.50 & 0.75 & 1.00 \\
\hline \multirow{6}{*}{0.25} & \multirow{3}{*}{ Popular } & $\mu$ & 156293 & 145048 & 135602 & 124562 & 94531 \\
\hline & & $\sigma$ & 19537 & 13184 & 19320 & 21327 & 21171 \\
\hline & & $\mathrm{CV}$ & 0.125 & 0.091 & 0.142 & 0.171 & 0.224 \\
\hline & \multirow{3}{*}{ Ganancioso } & $\mu$ & 60190 & 72697 & 85010 & 96487 & 127646 \\
\hline & & $\sigma$ & 16290 & 13612 & 19964 & 21738 & 19075 \\
\hline & & $\mathrm{CV}$ & 0.271 & 0.187 & 0.235 & 0.225 & 0.149 \\
\hline \multirow{6}{*}{0.5} & \multirow{3}{*}{ Popular } & $\mu$ & 168118 & 152456 & 143059 & 126167 & 92048 \\
\hline & & $\sigma$ & 9457 & 17390 & 21099 & 23313 & 20462 \\
\hline & & $\mathrm{CV}$ & 0.056 & 0.114 & 0.147 & 0.185 & 0.222 \\
\hline & \multirow{3}{*}{ Ganancioso } & $\mu$ & 45098 & 62463 & 77212 & 97721 & 132103 \\
\hline & & $\sigma$ & 9065 & 16717 & 20969 & 23571 & 18516 \\
\hline & & $\mathrm{CV}$ & 0.201 & 0.268 & 0.272 & 0.241 & 0.140 \\
\hline \multirow{6}{*}{0.75} & \multirow{3}{*}{ Popular } & $\mu$ & 168798 & 160966 & 145986 & 116628 & 63974 \\
\hline & & $\sigma$ & 15987 & 16725 & 21721 & 26848 & 19679 \\
\hline & & $\mathrm{CV}$ & 0.095 & 0.104 & 0.149 & 0.230 & 0.308 \\
\hline & \multirow{3}{*}{ Ganancioso } & $\mu$ & 44488 & 56285 & 75355 & 107151 & 158644 \\
\hline & & $\sigma$ & 15687 & 14248 & 20948 & 25414 & 16510 \\
\hline & & $\mathrm{CV}$ & 0.353 & 0.253 & 0.278 & 0.237 & 0.104 \\
\hline \multirow{6}{*}{1.0} & \multirow{3}{*}{ Popular } & $\mu$ & 170901 & 156853 & 125278 & 110703 & 41667 \\
\hline & & $\sigma$ & 12332 & 18951 & 18443 & 21023 & 21295 \\
\hline & & $\mathrm{CV}$ & 0.072 & 0.121 & 0.147 & 0.190 & 0.511 \\
\hline & \multirow{3}{*}{ Ganancioso } & $\mu$ & 38992 & 59511 & 95564 & 115177 & 180942 \\
\hline & & $\sigma$ & 13329 & 18072 & 18716 & 20735 & 18579 \\
\hline & & $\mathrm{CV}$ & 0.342 & 0.304 & 0.196 & 0.180 & 0.103 \\
\hline
\end{tabular}

(b) Pontualidade por taxa de mentirosos $\lambda$

\begin{tabular}{|c|c|c|c|c|c|c|c|}
\hline$\epsilon$ & Perfil & $\lambda$ & 0.00 & 0.25 & 0.50 & 0.75 & 1.00 \\
\hline \multirow{6}{*}{0.25} & \multirow{3}{*}{ Popular } & $\mu$ & 0.729 & 0.753 & 0.757 & 0.747 & 0.767 \\
\hline & & $\sigma$ & 0.037 & 0.018 & 0.021 & 0.020 & 0.021 \\
\hline & & $\mathrm{CV}$ & 0.051 & 0.024 & 0.028 & 0.027 & 0.027 \\
\hline & \multirow{3}{*}{ Ganancioso } & $\mu$ & 0.459 & 0.469 & 0.501 & 0.497 & 0.526 \\
\hline & & $\sigma$ & 0.049 & 0.032 & 0.043 & 0.036 & 0.032 \\
\hline & & $\mathrm{CV}$ & 0.107 & 0.068 & 0.086 & 0.072 & 0.061 \\
\hline \multirow{6}{*}{0.5} & \multirow{3}{*}{ Popular } & $\mu$ & 0.690 & 0.730 & 0.744 & 0.769 & 0.769 \\
\hline & & $\sigma$ & 0.032 & 0.028 & 0.033 & 0.018 & 0.023 \\
\hline & & $\mathrm{CV}$ & 0.046 & 0.038 & 0.044 & 0.023 & 0.030 \\
\hline & \multirow{3}{*}{ Ganancioso } & $\mu$ & 0.420 & 0.470 & 0.485 & 0.508 & 0.516 \\
\hline & & $\sigma$ & 0.036 & 0.038 & 0.043 & 0.043 & 0.043 \\
\hline & & $\mathrm{CV}$ & 0.086 & 0.081 & 0.089 & 0.085 & 0.083 \\
\hline \multirow{6}{*}{0.75} & \multirow{3}{*}{ Popular } & $\mu$ & 0.674 & 0.697 & 0.724 & 0.752 & 0.754 \\
\hline & & $\sigma$ & 0.038 & 0.032 & 0.040 & 0.030 & 0.022 \\
\hline & & $\mathrm{CV}$ & 0.056 & 0.046 & 0.055 & 0.040 & 0.029 \\
\hline & \multirow{3}{*}{ Ganancioso } & $\mu$ & 0.398 & 0.444 & 0.445 & 0.466 & 0.498 \\
\hline & & $\sigma$ & 0.051 & 0.037 & 0.041 & 0.045 & 0.047 \\
\hline & & $\mathrm{CV}$ & 0.128 & 0.083 & 0.092 & 0.097 & 0.094 \\
\hline \multirow{6}{*}{1.0} & \multirow{3}{*}{ Popular } & $\mu$ & 0.609 & 0.647 & 0.695 & 0.717 & 0.716 \\
\hline & & $\sigma$ & 0.039 & 0.053 & 0.038 & 0.037 & 0.037 \\
\hline & & $\mathrm{CV}$ & 0.064 & 0.082 & 0.055 & 0.052 & 0.052 \\
\hline & \multirow{3}{*}{ Ganancioso } & $\mu$ & 0.351 & 0.388 & 0.418 & 0.429 & 0.449 \\
\hline & & $\sigma$ & 0.034 & 0.047 & 0.040 & 0.051 & 0.042 \\
\hline & & $\mathrm{CV}$ & 0.097 & 0.121 & 0.096 & 0.119 & 0.094 \\
\hline
\end{tabular}

Para todos os valores de chances de sugestões dos pares $\epsilon$, percebe-se que, conforme a taxa de mentirosos $(\lambda)$ aumenta, o capital acumulado por agentes gananciosos também aumenta, enquanto o acumulado por agentes populares diminui. A pontualidade média, por sua vez, cresce com o aumento de $\lambda$.

\subsubsection{Experimento 3 - efeito de reputações sinceras}

Neste experimento, todos os agentes foram programados para dizer a verdade $(\lambda=0)$, e foram submetidos a diferentes taxas de disseminação de reputação ( $\gamma$ variando de 0,0 a 1,0 com 0,1 incremento). Cada cenário foi executado 20 vezes, com resultados para cada perfil mapeado nas Tabelas 5.6 (capital acumulado) e 5.7 (pontualidade).

Tabela 5.6 - Capital acumulado por taxa de disseminação de reputação $\gamma$

\begin{tabular}{|l|l|l|l|l|l|l|l|l|l|l|l|l|}
\hline Perfil & $\gamma$ & 0.0 & 0.1 & 0.2 & 0.3 & 0.4 & 0.5 & 0.6 & 0.7 & 0.8 & 0.9 & 1.0 \\
\hline \multirow{3}{*}{ Popular } & $\mu$ & 98411 & 149910 & 137211 & 145333 & 142489 & 145075 & 146667 & 147963 & 147522 & 146102 & 137756 \\
\cline { 2 - 12 } & $\sigma$ & 24875 & 25591 & 18839 & 23132 & 25172 & 16095 & 21134 & 19749 & 21972 & 21745 & 23600 \\
\cline { 2 - 12 } & $\mathrm{CV}$ & 0.253 & 0.171 & 0.137 & 0.159 & 0.177 & 0.111 & 0.144 & 0.133 & 0.149 & 0.149 & 0.171 \\
\hline \multirow{3}{*}{ Ganancioso } & $\mu$ & 123376 & 56259 & 59994 & 47102 & 44496 & 41798 & 36705 & 30761 & 29972 & 30080 & 30730 \\
\cline { 2 - 12 } & $\sigma$ & 22027 & 22941 & 19118 & 19589 & 20825 & 14086 & 20480 & 19475 & 19848 & 18683 & 21912 \\
\cline { 2 - 12 } & $\mathrm{CV}$ & 0.179 & 0.408 & 0.319 & 0.416 & 0.468 & 0.337 & 0.558 & 0.633 & 0.662 & 0.621 & 0.713 \\
\hline
\end{tabular}


Tabela 5.7 - Pontualidade por taxa de disseminação de reputação $\gamma$

\begin{tabular}{|l|l|l|l|l|l|l|l|l|l|l|l|l|}
\hline Perfil & $\gamma$ & 0.0 & 0.1 & 0.2 & 0.3 & 0.4 & 0.5 & 0.6 & 0.7 & 0.8 & 0.9 & 1.0 \\
\hline \multirow{3}{*}{ Popular } & $\mu$ & 0.755 & 0.694 & 0.666 & 0.617 & 0.602 & 0.604 & 0.579 & 0.574 & 0.555 & 0.547 & 0.543 \\
\cline { 2 - 12 } & $\sigma$ & 0.025 & 0.042 & 0.029 & 0.047 & 0.026 & 0.037 & 0.037 & 0.033 & 0.032 & 0.036 & 0.020 \\
\cline { 2 - 12 } & $\mathrm{CV}$ & 0.033 & 0.061 & 0.044 & 0.076 & 0.043 & 0.061 & 0.064 & 0.057 & 0.058 & 0.066 & 0.037 \\
\hline \multirow{3}{*}{ Ganancioso } & $\mu$ & 0.504 & 0.457 & 0.441 & 0.419 & 0.411 & 0.418 & 0.398 & 0.371 & 0.370 & 0.365 & 0.350 \\
\cline { 2 - 11 } & $\sigma$ & 0.033 & 0.040 & 0.050 & 0.046 & 0.049 & 0.039 & 0.043 & 0.028 & 0.049 & 0.029 & 0.025 \\
\cline { 2 - 11 } & $\mathrm{CV}$ & 0.065 & 0.088 & 0.113 & 0.110 & 0.119 & 0.093 & 0.108 & 0.075 & 0.132 & 0.079 & 0.071 \\
\hline
\end{tabular}

Analogamente ao observado no experimento 1 , neste experimento o aumento da taxa de disseminação de reputação $\gamma$ ocasiona o aumento do capital acumulado pelos agentes populares, a diminuição do capital acumulado pelos gananciosos e a diminuição da pontualidade média.

\subsubsection{Experimento 4 - efeito de reputações mentirosas}

Neste experimento, 5 taxas diferentes de mentirosos foram testadas ( $\lambda$ variando de 0,0 a 1,0 com incremento de 0,25$)$, combinado com 4 taxas de disseminação de reputação ( $\gamma$ com valores $0,25,0,5,0,75$ e 1,0), para um total de 20 cenários. Mais uma vez, cada cenário foi executado 20 vezes, com resultados na Tabela 5.8 .

Tabela 5.8 - Experimento 4

(a) Capital acumulado por taxa de mentirosos $\lambda$

\begin{tabular}{|c|c|c|c|c|c|c|c|}
\hline$\gamma$ & Perfil & $\lambda$ & 0.00 & 0.25 & 0.50 & 0.75 & 1.00 \\
\hline \multirow{6}{*}{0.25} & \multirow{3}{*}{ Popular } & $\mu$ & 147065 & 138051 & 129374 & 110945 & 105643 \\
\hline & & $\sigma$ & 23219 & 24536 & 28138 & 28851 & 18412 \\
\hline & & $\mathrm{CV}$ & 0.158 & 0.178 & 0.217 & 0.260 & 0.174 \\
\hline & \multirow{3}{*}{ Ganancioso } & $\mu$ & 49769 & 62147 & 78069 & 101428 & 113183 \\
\hline & & $\sigma$ & 20575 & 25936 & 25319 & 27147 & 17222 \\
\hline & & $\mathrm{CV}$ & 0.413 & 0.417 & 0.324 & 0.268 & 0.152 \\
\hline \multirow{6}{*}{0.5} & \multirow{3}{*}{ Popular } & $\mu$ & 145997 & 135610 & 123562 & 104813 & 90698 \\
\hline & & $\sigma$ & 21881 & 24265 & 22951 & 21167 & 21024 \\
\hline & & $\mathrm{CV}$ & 0.150 & 0.179 & 0.186 & 0.202 & 0.232 \\
\hline & \multirow{3}{*}{ Ganancioso } & $\mu$ & 38009 & 60754 & 82125 & 107287 & 130262 \\
\hline & & $\sigma$ & 21219 & 21928 & 19373 & 20378 & 19290 \\
\hline & & $\mathrm{CV}$ & 0.558 & 0.361 & 0.236 & 0.190 & 0.148 \\
\hline \multirow{6}{*}{0.75} & \multirow{3}{*}{ Popular } & $\mu$ & 143358 & 137487 & 122796 & 94269 & 71518 \\
\hline & & $\sigma$ & 19696 & 21344 & 24264 & 13840 & 15419 \\
\hline & & $\mathrm{CV}$ & 0.137 & 0.155 & 0.198 & 0.147 & 0.216 \\
\hline & \multirow{3}{*}{ Ganancioso } & $\mu$ & 31672 & 52361 & 76572 & 118140 & 144317 \\
\hline & & $\sigma$ & 14285 & 19198 & 24970 & 12993 & 13012 \\
\hline & & $\mathrm{CV}$ & 0.451 & 0.367 & 0.326 & 0.110 & 0.090 \\
\hline \multirow{6}{*}{1.0} & \multirow{3}{*}{ Popular } & $\mu$ & 147355 & 136184 & 121257 & 93567 & 68194 \\
\hline & & $\sigma$ & 21570 & 20948 & 32007 & 18802 & 15965 \\
\hline & & $\mathrm{CV}$ & 0.146 & 0.154 & 0.264 & 0.201 & 0.234 \\
\hline & \multirow{3}{*}{ Ganancioso } & $\mu$ & 25320 & 51405 & 79623 & 120918 & 150808 \\
\hline & & $\sigma$ & 19472 & 22470 & 30721 & 18838 & 14082 \\
\hline & & $\mathrm{CV}$ & 0.769 & 0.437 & 0.386 & 0.156 & 0.093 \\
\hline
\end{tabular}

(b) Pontualidade por taxa de mentirosos $\lambda$

\begin{tabular}{|c|c|c|c|c|c|c|c|}
\hline$\gamma$ & Perfil & $\lambda$ & 0.00 & 0.25 & 0.50 & 0.75 & 1.00 \\
\hline \multirow{6}{*}{0.25} & \multirow{3}{*}{ Popular } & $\mu$ & 0.648 & 0.575 & 0.505 & 0.434 & 0.334 \\
\hline & & $\sigma$ & 0.029 & 0.036 & 0.048 & 0.038 & 0.043 \\
\hline & & $\mathrm{CV}$ & 0.045 & 0.063 & 0.095 & 0.088 & 0.129 \\
\hline & \multirow{3}{*}{ Ganancioso } & $\mu$ & 0.439 & 0.422 & 0.422 & 0.398 & 0.374 \\
\hline & & $\sigma$ & 0.046 & 0.038 & 0.023 & 0.041 & 0.039 \\
\hline & & $\mathrm{CV}$ & 0.105 & 0.090 & 0.055 & 0.103 & 0.104 \\
\hline \multirow{6}{*}{0.5} & \multirow{3}{*}{ Popular } & $\mu$ & 0.588 & 0.531 & 0.437 & 0.377 & 0.278 \\
\hline & & $\sigma$ & 0.024 & 0.032 & 0.024 & 0.040 & 0.030 \\
\hline & & $\mathrm{CV}$ & 0.041 & 0.060 & 0.055 & 0.106 & 0.108 \\
\hline & \multirow{3}{*}{ Ganancioso } & $\mu$ & 0.396 & 0.388 & 0.383 & 0.360 & 0.326 \\
\hline & & $\sigma$ & 0.045 & 0.053 & 0.040 & 0.039 & 0.043 \\
\hline & & $\mathrm{CV}$ & 0.114 & 0.137 & 0.104 & 0.108 & 0.132 \\
\hline \multirow{6}{*}{0.75} & \multirow{3}{*}{ Popular } & $\mu$ & 0.561 & 0.517 & 0.456 & 0.366 & 0.270 \\
\hline & & $\sigma$ & 0.030 & 0.033 & 0.025 & 0.026 & 0.023 \\
\hline & & $\mathrm{CV}$ & 0.053 & 0.064 & 0.055 & 0.071 & 0.085 \\
\hline & \multirow{3}{*}{ Ganancioso } & $\mu$ & 0.358 & 0.363 & 0.358 & 0.349 & 0.326 \\
\hline & & $\sigma$ & 0.034 & 0.046 & 0.036 & 0.039 & 0.032 \\
\hline & & $\mathrm{CV}$ & 0.095 & 0.127 & 0.101 & 0.112 & 0.098 \\
\hline \multirow{6}{*}{1.0} & \multirow{3}{*}{ Popular } & $\mu$ & 0.563 & 0.508 & 0.439 & 0.373 & 0.267 \\
\hline & & $\sigma$ & 0.027 & 0.021 & 0.033 & 0.022 & 0.023 \\
\hline & & $\mathrm{CV}$ & 0.048 & 0.041 & 0.075 & 0.059 & 0.086 \\
\hline & \multirow{3}{*}{ Ganancioso } & $\mu$ & 0.348 & 0.360 & 0.354 & 0.351 & 0.306 \\
\hline & & $\sigma$ & 0.043 & 0.029 & 0.035 & 0.030 & 0.032 \\
\hline & & $\mathrm{CV}$ & 0.124 & 0.081 & 0.099 & 0.085 & 0.105 \\
\hline
\end{tabular}


Analogamente ao observado no experimento 2 , conforme a taxa de mentirosos $(\lambda)$ aumenta, o capital acumulado por agentes gananciosos aumenta, enquanto o acumulado por agentes populares diminui, para todos os valores de taxa de disseminação de reputação $\gamma$. Já a pontualidade média diminui com o aumento de $\lambda$, contrariando o resultado obtido no experimento 2 com o aumento de $\epsilon$.

\subsection{Análise dos resultados}

Nesta seção, são apresentadas as análises dos resultados dos experimentos descritos na seção 5.4. A seguir, na subseção 5.5.1 o método de análise é detalhado, enquanto nas subseções 5.5.2, 5.5.3, 5.5.4 e 5.5.5 o método é aplicado para responder às perguntas da seção 1.2 .

\subsubsection{Método de análise}

O método usado para analisar os resultados experimentais é baseado em um processo chamado teste de hipóteses (BOSLAUGH; WATTERS, 2008). Este método provê uma regra de decisão direcionada a aceitar ou rejeitar uma hipótese estatística a partir de elementos amostrais. Para isso, formulam-se duas hipóteses, a principal (HO) e a alternativa(H1). A hipótese alternativa normalmente é formulada como sendo a suposição que se deseja provar, enquanto a hipótese nula é formulada para se rejeitar. Deste modo, ao rejeitar H0, aceita-se H1.

No presente trabalho, nem todos as amostras de dados a serem analisados possuem distribuição normal. Por esse motivo, adota-se aqui o teste de hipóteses não paramétrico denominado Teste da Soma das Ordens de Willcoxon ${ }^{2}$ (BOSLAUGH; WATTERS, 2008).

Para o cálculo acima, supõem-se dois conjuntos, A e B, a serem comparados. Primeiramente, unem-se os valores dos dois conjuntos e ordenam-se do menor para 0 maior. Para cada valor, atribui-se um número de posição, de forma que ao menor valor atribui-se o número 1, ao segundo menor o número 2, e assim sucessivamente. Caso haja números repetidos, somam-se os números das posições, divide-se o resultado pelo número de repetições e atribui-se o valor resultante a cada uma das repetições. Após esta etapa, somam-se os números de posição para os valores de cada grupo, obtendo-se $W_{A}$ e $W_{B}$. A partir do mínimo $W$ entre $W_{A}$ e $W_{B}$, calcula-se o valor de $Z$ para determinar se a diferença entre os grupos é estatisticamente significante, de acordo com a Equação 5.1 .

$$
Z=\frac{W-\mu_{W}}{\sigma_{W}}
$$

\footnotetext{
2 do inglês "Willcoxon's Rank Sum Test"
} 
onde $\mu_{W}$ - soma esperada de $W$, obtida pela equação 5.2 $\sigma_{W}$ - desvio padrão de $W$, obtido pela equação 5.3

$$
\begin{gathered}
\mu_{W}=\frac{n_{A}\left(n_{A}+n_{B}+1\right)}{2} \\
\sigma_{W}=\sqrt{\frac{n_{A} n_{B}\left(n_{A}+n_{B}+1\right)}{12}}
\end{gathered}
$$

com $n_{X}$ - número de elementos na amostra $X$.

Por fim, toma-se o valor calculado de $Z$ para se obter o valor de $\mathrm{p}$ por meio da tabela de distribuição normal. Caso $\mathrm{p}$ seja menor ou igual ao valor de significância $\alpha$ estipulado, rejeita-se $\mathrm{H} 0$ e aceita-se H1. Caso contrário, não se rejeita H0. Tais análises estatísticas foram preliminarmente apresentadas em (JALBUT; SICHMAN, 2018b).

\subsubsection{Hipóteses para a pergunta 1}

O tipo de estratégia adotada pelos agentes afeta o capital acumulado e a pontualidade de suas entregas?

Hipótese A No cenário sem sugestões e reputações, agentes gananciosos acumulam mais capital que agentes populares. Esta hipótese é expressa matematicamente como:

$\bar{\Delta} C_{g}^{\epsilon=0, \gamma=0, \lambda=0}>\bar{\Delta} C_{p}^{\epsilon=0, \gamma=0, \lambda=0}$

Para validar a hipótese, faz-se o teste:

H0: $\bar{\Delta} C_{g}^{\epsilon=0, \gamma=0, \lambda=0}<=\bar{\Delta} C_{p}^{\epsilon=0, \gamma=0, \lambda=0}$

$\mathrm{H} 1: \bar{\Delta} C_{g}^{\epsilon=0, \gamma=0, \lambda=0}>\bar{\Delta} C_{p}^{\epsilon=0, \gamma=0, \lambda=0}$

Hipótese B No cenário sem sugestões e reputações, agentes gananciosos são menos pontuais que agentes populares. Esta hipótese é expressa matematicamente como:

$\overline{\text { Trust }}_{g}^{\epsilon=0, \gamma=0, \lambda=0}<\bar{\Delta} C_{p}^{\epsilon=0, \gamma=0, \lambda=0}$

Para validar a hipótese, faz-se o teste:

H0: $\overline{\text { Trust }}_{g}^{\epsilon=0, \gamma=0, \lambda=0}>=\bar{\Delta} C_{p}^{\epsilon=0, \gamma=0, \lambda=0}$

$\mathrm{H} 1: \overline{\text { Trust }}_{g}^{\epsilon=0, \gamma=0, \lambda=0}<\bar{\Delta} C_{p}^{\epsilon=0, \gamma=0, \lambda=0}$

Tabela 5.9 - Hipóteses para a pergunta 1

\begin{tabular}{|l|l|l|}
\hline Hipótese & $\mathrm{A}$ & $\mathrm{B}$ \\
\hline Valor de $\mathrm{p}$ & 0,003 & 0,000 \\
\hline
\end{tabular}


A Tabela 5.9 mostra que os valores de $p$ são menores que 0,05 , suficiente para rejeitar H0 para a Hipótese A e a Hipótese B. Isso significa que, no cenário padrão sem pedidos de sugestões e disseminação de recomendações, os agentes gananciosos de fato são menos pontuais que os agentes populares, uma vez que, ao contrário dos primeiros, estes últimos armazenam estoque de segurança, e este estoque contribui para garantir as entregas em situações de demanda acima do previsto. Também revela que, ainda assim, os agentes gananciosos conseguem acumular mais capital que os populares, devido à maior margem de lucro praticada por aqueles em relação a estes.

\subsubsection{Hipóteses para a pergunta 2}

A troca de sugestões de fornecedores entre clientes afeta o capital acumulado e a pontualidade de entrega dos agentes?

Hipótese C A troca de sugestões de fornecedores entre clientes aumenta o capital acumulado pelos agentes populares. Esta hipótese é expressa matematicamente como:

$\bar{\Delta} C_{p}^{\epsilon=1, \gamma=0, \lambda=0}>\bar{\Delta} C_{p}^{\epsilon=0, \gamma=0, \lambda=0}$

Para validar a hipótese, faz-se o teste:

$\mathrm{H} 0: \bar{\Delta} C_{p}^{\epsilon=1, \gamma=0, \lambda=0}<=\bar{\Delta} C_{p}^{\epsilon=0, \gamma=0, \lambda=0}$

$\mathrm{H} 1: \bar{\Delta} C_{p}^{\epsilon=1, \gamma=0, \lambda=0}>\bar{\Delta} C_{p}^{\epsilon=0, \gamma=0, \lambda=0}$

Hipótese D A troca de sugestões de fornecedores entre clientes diminui o capital acumulado pelos agentes gananciosos. Esta hipótese é expressa matematicamente como:

$\bar{\Delta} C_{g}^{\epsilon=1, \gamma=0, \lambda=0}<\bar{\Delta} C_{g}^{\epsilon=0, \gamma=0, \lambda=0}$

Para validar a hipótese, faz-se o teste:

$\mathrm{H} 0: \bar{\Delta} C_{g}^{\epsilon=1, \gamma=0, \lambda=0}>=\bar{\Delta} C_{g}^{\epsilon=0, \gamma=0, \lambda=0}$

$\mathrm{H} 1: \bar{\Delta} C_{g}^{\epsilon=1, \gamma=0, \lambda=0}<\bar{\Delta} C_{g}^{\epsilon=0, \gamma=0, \lambda=0}$

Hipótese E A troca de sugestões de fornecedores entre clientes diminui a pontualidade dos agentes como um todo. Esta hipótese é expressa matematicamente como:

$\overline{\text { Trust }}^{\epsilon=1, \gamma=0, \lambda=0}<\overline{\text { Trust }}^{\epsilon=0, \gamma=0, \lambda=0}$

Para validar a hipótese, faz-se o teste:

H0: $\overline{\text { Trust }}^{\epsilon=1, \gamma=0, \lambda=0}>=\overline{\text { Trust }}^{\epsilon=0, \gamma=0, \lambda=0}$

H1: $\overline{\text { Trust }}^{\epsilon=1, \gamma=0, \lambda=0}<\overline{\text { Trust }}^{\epsilon=0, \gamma=0, \lambda=0}$ 
Tabela 5.10 - Hipóteses para a pergunta 2

\begin{tabular}{|l|l|l|l|}
\hline Hipótese & $\mathrm{C}$ & $\mathrm{D}$ & $\mathrm{E}$ \\
\hline Valor de $\mathrm{p}$ & 0,000 & 0,000 & 0,000 \\
\hline
\end{tabular}

Podemos verificar, na Tabela 5.10 que, com o aumento de $\epsilon$, o capital acumulado tende a aumentar para os agentes populares ( $\mathrm{H} 0$ rejeitada na Hipótese $\mathrm{C}$ ) e diminuir para os gananciosos ( $\mathrm{H} 0$ rejeitada na Hipótese $\mathrm{D}$ ). A razão para isso é que, a longo prazo, tanto os agentes populares quanto os gananciosos tendem a buscar fornecedores populares, os primeiros buscando taxas de confiança mais altas para garantir as entregas dos clientes e os segundos buscando preços de compra mais baixos para alcançar margens de lucro mais altas. Como consequência, todos tendem a alterar seus fornecedores no curso da simulação. Também é possível rejeitar H0 para a Hipótese $E$, porque a presença de sugestões incentiva clientes a mudar de fornecedor com mais frequência, o que dificulta a previsão de demanda por parte dos fornecedores e provoca a diminuição da pontualidade com o aumento de $\epsilon$.

\subsubsection{Hipóteses para a pergunta 3}

A presença de agentes mentirosos tem efeito no capital acumulado e na pontualidade de entrega dos agentes?

Hipótese F Quando há troca de sugestões, a presença de clientes mentirosos diminui o capital acumulado pelos agentes populares. Esta hipótese é expressa matematicamente como:

$\bar{\Delta} C_{p}^{\epsilon=1, \gamma=0, \lambda=1}<\bar{\Delta} C_{p}^{\epsilon=1, \gamma=0, \lambda=0}$

Para validar a hipótese, faz-se o teste:

H0: $\bar{\Delta} C_{p}^{\epsilon=1, \gamma=0, \lambda=1}>=\bar{\Delta} C_{p}^{\epsilon=1, \gamma=0, \lambda=0}$

$\mathrm{H} 1: \bar{\Delta} C_{p}^{\epsilon=1, \gamma=0, \lambda=1}<\bar{\Delta} C_{p}^{\epsilon=1, \gamma=0, \lambda=0}$

Hipótese G Quando há troca de sugestões, a presença de clientes mentirosos aumenta o capital acumulado pelos agentes gananciosos. Esta hipótese é expressa matematicamente como:

$\bar{\Delta} C_{g}^{\epsilon=1, \gamma=0, \lambda=1}>\bar{\Delta} C_{g}^{\epsilon=1, \gamma=0, \lambda=0}$

Para validar a hipótese, faz-se o teste:

H0: $\bar{\Delta} C_{g}^{\epsilon=1, \gamma=0, \lambda=1}<=\bar{\Delta} C_{g}^{\epsilon=1, \gamma=0, \lambda=0}$

$\mathrm{H} 1: \bar{\Delta} C_{g}^{\epsilon=1, \gamma=0, \lambda=1}>\bar{\Delta} C_{g}^{\epsilon=1, \gamma=0, \lambda=0}$ 
Hipótese H Quando há troca de sugestões, a presença de clientes mentirosos diminui a pontualidade dos agentes como um todo. Esta hipótese é expressa matematicamente como:

$\overline{\text { Trust }}^{\epsilon=1, \gamma=0, \lambda=1}<\overline{\text { Trust }}^{\epsilon=1, \gamma=0, \lambda=0}$

Para validar a hipótese, faz-se o teste:

H0: $\overline{\text { Trust }}^{\epsilon=1, \gamma=0, \lambda=1}>=\overline{\text { Trust }}^{\epsilon=1, \gamma=0, \lambda=0}$

H1: $\overline{\text { Trust }}^{\epsilon=1, \gamma=0, \lambda=1}<\overline{\text { Trust }}^{\epsilon=1, \gamma=0, \lambda=0}$

Tabela 5.11 - Hipóteses para a pergunta 3

\begin{tabular}{|l|l|l|l|}
\hline Hipótese & $\mathrm{F}$ & $\mathrm{G}$ & $\mathrm{H}$ \\
\hline Valor de p & 0,000 & 0,000 & 1,000 \\
\hline
\end{tabular}

É possível observar que uma maior proporção de mentirosos diminui o capital acumulado por agentes populares ( $\mathrm{H} 0$ rejeitada na Hipótese F) e aumenta o acumulado por agentes gananciosos ( $\mathrm{H} 0$ rejeitada na Hipótese G), já que as falsas recomendações fornecidas pelos mentirosos tendem a apontar fornecedores caros e não pontuais, que são em sua maioria gananciosos. Por outro lado, ao contrário do que prevê a Hipótese $\mathrm{H}$, a pontualidade média dos agentes não diminuiu com o aumento de mentirosos (H0 não rejeitada). Um possível motivo é que sugestões mentirosas seriam menos atendidas que sugestões sinceras, o que levaria a uma redução do número de trocas de fornecedor, à fixação dos clientes de cada fornecedor, e portanto à facilitação da previsão e entrega dos pedidos pelos fornecedores aos clientes.

\subsubsection{Hipóteses para a pergunta 4}

A disseminação de reputação tem efeito no capital acumulado e na pontualidade de entrega dos agentes?

Hipótese I A disseminação de reputações de fornecedores entre clientes aumenta o capital acumulado pelos agentes populares. Esta hipótese é expressa matematicamente como:

$\bar{\Delta} C_{p}^{\epsilon=0, \gamma=1, \lambda=0}>\bar{\Delta} C_{p}^{\epsilon=0, \gamma=0, \lambda=0}$

Para validar a hipótese, faz-se o teste:

$\mathrm{H} 0: \bar{\Delta} C_{p}^{\epsilon=0, \gamma=1, \lambda=0}<=\bar{\Delta} C_{p}^{\epsilon=0, \gamma=0, \lambda=0}$

$\mathrm{H} 1: \bar{\Delta} C_{p}^{\epsilon=0, \gamma=1, \lambda=0}>\bar{\Delta} C_{p}^{\epsilon=0, \gamma=0, \lambda=0}$ 
Hipótese J A disseminação de reputações de fornecedores entre clientes diminui o capital acumulado pelos agentes gananciosos. Esta hipótese é expressa matematicamente como:

$\bar{\Delta} C_{g}^{\epsilon=0, \gamma=1, \lambda=0}<\bar{\Delta} C_{g}^{\epsilon=0, \gamma=0, \lambda=0}$

Para validar a hipótese, faz-se o teste:

H0: $\bar{\Delta} C_{g}^{\epsilon=0, \gamma=1, \lambda=0}>=\bar{\Delta} C_{g}^{\epsilon=0, \gamma=0, \lambda=0}$

$\mathrm{H} 1: \bar{\Delta} C_{g}^{\epsilon=0, \gamma=1, \lambda=0}<\bar{\Delta} C_{g}^{\epsilon=0, \gamma=0, \lambda=0}$

Hipótese K A disseminação de reputações de fornecedores entre clientes diminui a pontualidade dos agentes como um todo. Esta hipótese é expressa matematicamente como:

$\overline{\text { Trust }}^{\epsilon=0, \gamma=1, \lambda=0}<\overline{\text { Trust }}^{\epsilon=0, \gamma=0, \lambda=0}$

Para validar a hipótese, faz-se o teste:

H0: $\overline{\text { Trust }}^{\epsilon=0, \gamma=1, \lambda=0}>=\overline{\text { Trust }}^{\epsilon=0, \gamma=0, \lambda=0}$

H1: $\overline{\text { Trust }}^{\epsilon=0, \gamma=1, \lambda=0}<\overline{\text { Trust }}^{\epsilon=0, \gamma=0, \lambda=0}$

Hipótese L Quando há disseminação de reputações, a presença de clientes mentirosos diminui o capital acumulado pelos agentes populares. Esta hipótese é expressa matematicamente como:

$\bar{\Delta} C_{p}^{\epsilon=0, \gamma=1, \lambda=1}<\bar{\Delta} C_{p}^{\epsilon=0, \gamma=1, \lambda=0}$

Para validar a hipótese, faz-se o teste:

$\mathrm{HO}: \bar{\Delta} C_{p}^{\epsilon=0, \gamma=1, \lambda=1}>=\bar{\Delta} C_{p}^{\epsilon=0, \gamma=1, \lambda=0}$

$\mathrm{H} 1: \bar{\Delta} C_{p}^{\epsilon=0, \gamma=1, \lambda=1}<\bar{\Delta} C_{p}^{\epsilon=0, \gamma=1, \lambda=0}$

Hipótese M Quando há disseminação de reputações, a presença de clientes mentirosos aumenta o capital acumulado pelos agentes gananciosos. Esta hipótese é expressa matematicamente como:

$\bar{\Delta} C_{g}^{\epsilon=0, \gamma=1, \lambda=1}>\bar{\Delta} C_{g}^{\epsilon=0, \gamma=1, \lambda=0}$

Para validar a hipótese, faz-se o teste:

H0: $\bar{\Delta} C_{g}^{\epsilon=0, \gamma=1, \lambda=1}<=\bar{\Delta} C_{g}^{\epsilon=0, \gamma=1, \lambda=0}$

$\mathrm{H} 1: \bar{\Delta} C_{g}^{\epsilon=0, \gamma=1, \lambda=1}>\bar{\Delta} C_{g}^{\epsilon=0, \gamma=1, \lambda=0}$

Hipótese N Quando há disseminação de reputações, a presença de clientes mentirosos diminui a pontualidade dos agentes como um todo. Esta hipótese é expressa matematicamente como: 


$$
\overline{\text { Trust }}^{\epsilon=0, \gamma=1, \lambda=1}<\overline{\text { Trust }}^{\epsilon=0, \gamma=1, \lambda=0}
$$

Para validar a hipótese, faz-se o teste:

$$
\begin{aligned}
& \text { H0: } \overline{\text { Trust }}^{\epsilon=0, \gamma=1, \lambda=1}>=\overline{\text { Trust }}^{\epsilon=0, \gamma=1, \lambda=0} \\
& \text { H1: } \overline{\text { Trust }}^{\epsilon=0, \gamma=1, \lambda=1}<\overline{\text { Trust }}^{\epsilon=0, \gamma=1, \lambda=0}
\end{aligned}
$$

Tabela 5.12 - Hipóteses para a pergunta 4

\begin{tabular}{|l|l|l|l|l|l|l|}
\hline Hipótese & $\mathrm{I}$ & $\mathrm{J}$ & $\mathrm{K}$ & $\mathrm{L}$ & $\mathrm{M}$ & $\mathrm{N}$ \\
\hline Valor de p & 0,000 & 0,000 & 0,000 & 0,000 & 0,000 & 0,000 \\
\hline
\end{tabular}

Analogamente ao que ocorre com o uso de sugestões, o disseminação de reputações aumenta o capital acumulado por agentes populares ( $\mathrm{H} 0$ rejeitada na Hipótese I), diminui o acumulado por agentes gananciosos ( $\mathrm{H} 0$ rejeitada na Hipótese J) e também diminui a pontualidade ( $\mathrm{H} 0$ rejeitada na Hipótese $\mathrm{K}$ ), pelos mesmos motivos descritos na seção 5.5.5. Além disso, a presença de mentirosos provoca o efeito inverso, diminuindo o capital dos populares (H0 rejeitada na Hipótese $\mathrm{L}$ ) e aumentando o dos gananciosos ( $\mathrm{H} 0$ rejeitada na Hipótese $\mathrm{M}$ ), assim como constatado na seção 5.5.4. No entanto, diferentemente do que se observa no caso das sugestões, a disseminação de reputações por mentirosos de fato diminui a pontualidade dos agentes em geral $(\mathrm{H} 0$ rejeitada para Hipótese N), uma vez que o próprio mecanismo de reputações incrementa o histórico de entregas dos fornecedores. Como entregas pontuais são mais comuns que atrasos, os clientes mentirosos registram em média mais atrasos dos fornecedores com os quais interagiram que os clientes sinceros, o que provoca uma baixa nos índices de pontualidade acumulados.

\subsection{Síntese}

Este capítulo detalhou respectivamente nas Seções 5.1 e 5.2 o ambiente utilizado para a simulação e os parâmetros de entrada, bem como seus valores. Em seguida, a seção 5.3 apresentou o plano de experimentos destinados a responder às perguntas de pesquisa. A seção 5.4 apresentou os resultados produzidos pela execução em lote destes experimentos, e por fim na seção 5.5 realizou-se a análise dos resultados obtidos por meio de testes estatísticos.

Os resultados obtidos mostram que perfis distintos obtém resultados distintos quanto ao capital acumulado e à pontualidade das entregas, e que a disseminação de informação, seja por meio de informantes ou de reputação, tende a aumentar o capital acumulado de agentes populares e diminuir o capital acumulado de agentes gananciosos. Em contrapartida, a presença de mentirosos aumenta o capital acumulado de 
gananciosos e diminui o de populares. Quanto à pontualidade, ela diminui tanto com o uso de sugestões quanto de reputações. No caso de reputações, a presença de mentirosos agrava este efeito. 


\section{Conclusões}

Neste trabalho, foi utilizada uma abordagem de simulação baseada em agentes para simular uma SC usando a estrutura proposta pelo Beer Game. No experimento, foi possível observar o efeito dos diferentes perfis estratégicos de agente sobre o seu capital acumulado e pontualidade.

Em um cenário sem comunicação, observou-se também que uma estratégia que prioriza margem de lucro tende a acumular mais capital que uma que prioriza número de clientes devido ao fato de a primeira lucrar mais por pedido e de ter menos custo de manutenção de estoque. Contudo, a ausência deste estoque de segurança faz com que a sua pontualidade seja menor que a da segunda estratégia.

Verificou-se também que relacionamentos cliente-fornecedor baseados em confiança tendem a ser mais lucrativos quando há comunicação e sinceridade, enquanto decisões baseadas em preços prevalecem quando o silêncio e/ou informações falsas são a norma. Este efeito foi observado tanto com a presença de sugestões quanto de reputações.

Finalmente, constatou-se que o aumento da comunicação entre os agentes, seja via sugestões, seja via reputações, aumenta as trocas de fornecedor, o que dificulta a previsão de demanda, e, por conseguinte, diminui a pontualidade no atendimento dos pedidos. Já a presença de mentirosos provoca efeitos distintos: sugestões mentirosas desencorajam trocas de fornecedores e assim estabilizam o sistema aumentando a pontualidade, enquanto reputações mentirosas provocam mais trocas, instabilidade e atrasos.

Para experimentos futuros, seria interessante avaliar os benefícios individuais de mentir comparado a dizer a verdade, bem como analisar proporções desiguais de agentes populares e gananciosos, diferentes topologias de cadeia de fornecimento e valores diferentes para os parâmetros do Beer Game. Uma outra direção é permitir que agentes migrem entre perfis diferentes, de modo evolutivo, como proposto em (WOTTER et al., 2017). 


\section{Referências}

AKKERMANS, H. Emergent supply networks: system dynamics simulation of adaptive supply agents. In: Proceedings of the 34th Annual Hawaii International Conference on System Sciences. [S.I.]: IEEE Comput. Soc, 2001. p. 11. ISBN 0-7695-0981-9. ISSN 10603425.

ANGERHOFER, B. J.; ANGELIDES, M. C. System dynamics modelling in supply chain management: research review. Winter Simulation Conference, IEEE, v. 1, p. 342-351, 2000.

BEAMON, B. M. Measuring supply chain performance. International Journal of Operations \& Production Management, MCB University Press, v. 19, n. 3, p. 275-292, 1999. ISSN 0144-3577.

BOSLAUGH, S.; WATTERS, P. Statistics in a Nutshell: A Desktop Quick Reference. In a Nutshell. [S.I.]: O’Reilly). O'Reilly Media, 2008.

CHANG, A.-Y.; YU, H.-F.; YANG, T.-H. A study of the key factors contributing to the bullwhip effect in the supply chain of the retail industry. Journal of Industrial and Production Engineering, Taylor \& Francis, v. 30, n. 7, p. 433-442, 2013.

CHOI, T. Y.; DOOLEY, K. J.; RUNGTUSANATHAM, M. Supply networks and complex adaptive systems: Control versus emergence. Journal of Operations Management, v. 19, n. 3, p. 351-366, 2001. ISSN 02726963.

COLLIER, N. RePast : An Extensible Framework for Agent Simulation. The University of Chicagos Social Science Research, v. 36, p. 371-375, 2003. ISSN 0028-1042.

CROOM, S.; ROMANO, P.; GIANNAKIS, M. Supply chain management: an analytical framework for critical literature review. European journal of purchasing \& supply management, Elsevier, v. 6, n. 1, p. 67-83, 2000.

ECLIPSE, I. Eclipse Foundation. 2007.

EDALI, M.; YASARCANB, H. A Mathematical Model of the Beer Game. JASSS, 2014.

FORRESTER, J. W. Industrial dynamics. Journal of the Operational Research Society, Palgrave Macmillan, v. 48, n. 10, p. 1037-1041, 1997.

FRIEDMAN, M. The social responsibility of business is to increase its profits.

Corporate ethics and corporate governance, Springer, p. 173-178, 2007.

FUENTE, D. D. L.; LOZANO, J. Application of distributed intelligence to reduce the bullwhip effect. International Journal of Production Research, Taylor \& Francis, v. 45, n. 8, p. 1815-1833, 2007. 
GIARDINI, F.; TOSTO, G. D.; CONTE, R. A model for simulating reputation dynamics in industrial districts. Simulation Modelling Practice and Theory, Elsevier, v. 16, n. 2, p. 231-241, feb 2008. ISSN 1569190X.

HANDFIELD, R.; NICHOLS, J. EL (1999) Introduction to supply chain management. [S.I.]: Prentice-Hall, Inc..[52], 1999.

HANDFIELD, R. B.; BECHTEL, C. The role of trust and relationship structure in improving supply chain responsiveness. Industrial marketing management, Elsevier, v. 31, n. 4, p. 367-382, 2002.

HOLLAND, J. H.; MILLER, J. H. American Economic Association Artificial Adaptive Agents in Economic Theory. The American Economic Review, v. 81, n. 2, p. 365-370, 1991.

HOU, Y.; XIONG, Y.; WANG, X.; LIANG, X. The effects of a trust mechanism on a dynamic supply chain network. Expert Systems with Applications, Elsevier, v. 41, n. 6, p. 3060-3068, 2014. ISSN 09574174.

HUA, Z.; SUN, Y.; XU, X. Operational causes of bankruptcy propagation in supply chain. Decision Support Systems, v. 51, n. 3, p. 671-681, 2011. ISSN 01679236.

IRELAND, R. D.; WEBB, J. W. A multi-theoretic perspective on trust and power in strategic supply chains. Journal of Operations Management, v. 25, n. 2, p. 482-497, 2007. ISSN 02726963.

JALBUT, A. D. da S.; SICHMAN, J. S. Avaliação de modelos de confiança em cadeias de suprimentos simuladas por agentes. In: Anais do V Workshop de Pós-Graduação em Engenharia de Computação (WPGEC 2016). Escola Politécnica da Universidade de São Paulo, Brasil: [s.n.], 2016. p. 23-24.

JALBUT, A. D. da S.; SICHMAN, J. S. Impact of trust on agent-based simulation for supply chains. In: Proceedings of the 19th. International Workshop on Multi-Agent Systems and Agent-Based Simulation (MABS 2018). Stockholm, Sweden: [s.n.], 2018.

JALBUT, A. D. da S.; SICHMAN, J. S. Impacto da confiança em em simulação baseada em agentes para cadeias de suprimento. In: Anais do XII Workshop-Escola de Sistemas de Agentes, seus ambientes e aplicações (WESAAC 2018). Fortaleza, CE: [s.n.], 2018. p. 73-84.

KIM, W. S. Effects of a trust mechanism on complex adaptive supply networks: An agent-based social simulation study. JASSS, JASSS, v. 12, n. 3, 2009. ISSN 14607425.

KIMBROUGH, S. O.; WU, D. J.; ZHONG, F. Computers play the beer game: Can artificial agents manage supply chains? In: Decision Support Systems. [S.I.: s.n.], 2002. v. 33, n. 3, p. 323-333. ISBN 0-7695-0981-9. ISSN 01679236.

LAMBERT, D. M.; COOPER, M. C. Issues in supply chain management. Industrial marketing management, Elsevier, v. 29, n. 1, p. 65-83, 2000. 
LATTILA, L.; HILLETOFTH, P.; LIN, B. Hybrid simulation models - When, why, how? Expert Systems with Applications, v. 37, n. 12, p. 7969-7975, 2010. ISSN 09574174.

LEE, H. L.; PADMANABHAN, V.; WHANG, S. Information Distortion in a Supply Chain: The Bullwhip Effect. Source: Management Science, v. 43, n. 4, p. 546-558, 1997.

LIN, F.-r.; SUNG, Y.-W.; LO, Y.-P. Effects of trust mechanisms on supply-chain performance: A multi-agent simulation study. International Journal of Electronic Commerce, Taylor \& Francis, v. 9, n. 4, p. 9-112, 2005.

MAYER, R. C.; DAVIS, J. H.; SCHOORMAN, F. D. An integrative model of organizational trust. Academy of management review, Academy of Management, v. 20, n. 3, p. 709-734, 1995.

MINAR, N. The Swarm Simulation System : A Toolkit for Building Multi-agent Simulations. Simulation, p. 1-11, 1996.

MIZGIER, K. J.; WAGNER, S. M.; HOLYST, J. A. Modeling defaults of companies in multi-stage supply chain networks. International Journal of Production Economics, v. 135, n. 1, p. 14-23, 2012. ISSN 09255273.

MORGAN, R. M.; HUNT, S. D. The commitment-trust theory of relationship marketing. The journal of marketing, JSTOR, p. 20-38, 1994.

NAGURNEY, A. Supply chain network economics: dynamics of prices, flows and profits. [S.I.]: Edward Elgar Publishing, 2006.

OZIK, J.; COLLIER, N. T.; MURPHY, J. T.; NORTH, M. J. The relogo agent-based modeling language. In: IEEE. Simulation Conference (WSC), 2013 Winter. [S.I.], 2013. p. $1560-1568$.

PANAYIDES, P. M.; LUN, Y. V. The impact of trust on innovativeness and supply chain performance. International Journal of Production Economics, Elsevier, v. 122, n. 1, p. 35-46, 2009.

PARUNAK, H.; SAVIT, R.; RIOLO, R. Agent-based modeling vs. equation-based modeling: A case study and users' guide. Proceedings of Multi-agent systems and Agent-based Simulation (MABS'98), p. 10-25, 1998. ISSN 0302-9743.

PARUNAK, H. D. Go to the Ant: Engineering Principles from Natural Agent Systems. Annals of Operations Research, v. 75, p. 69-101, 1997. ISSN 0254-5330.

PHELAN, S. E. A Note on the Correspondence Between Complexity and Systems Theory. Systemic Practice and Action Research, v. 12, n. 3, 1999.

RINDFLEISCH, A.; HEIDE, J. B. Transaction cost analysis: Past, present, and future applications. the Journal of Marketing, JSTOR, p. 30-54, 1997.

RING, P. S.; VEN, A. H. V. D. Developmental processes of cooperative interorganizational relationships. Academy of Management Review, v. 19, n. 1, p. 90-118, 1994. ISSN 03637425. 
SCHIERITZ, N.; GRÖSSLER, A. Emergent structures in supply chains - A study integrating agent-based and system dynamics modeling. In: Proceedings of the 36th Annual Hawaii International Conference on System Sciences, HICSS 2003. [S.I.: s.n.], 2003. ISBN 0769518745.

SCHOLL, H. J. Agent based and system dynamics modeling: a call for cross study and joint research, 34th. Annual Hawaii International Conference on System Sciences ( HICSS-34)-Volume, v. 3pp, p. 3003, 2001.

SIMCHI-LEVI, D.; KAMINSKY, P.; SIMCHI-LEVI, E. Designing and managing the supply chain. Concepts, strategies, and case studies, McGraw-Hill Boston, v. 2, 2000.

STERMAN, J. Modeling managerial behavior-misperceptions of feedback in a dynamic decisionmaking experiment. Sloan School of Management, Massachusetts Institute of Technology, 1987.

STERMAN, J. D. Modeling managerial behavior: Misperceptions of feedback in a dynamic decision making experiment. Management science, INFORMS, v. 35, n. 3, p. 321-339, 1989.

STERMAN, J. D. Teaching Takes Off: Flight Simulators for Management Education. OR/MS Today, p. 40-44, 1992.

SWAMINATHAN, J. M.; SMITH, S. F.; SADEH, N. M. Modeling supply chain dynamics: A multiagent approach. Decision Sciences, v. 29, n. 3, p. 607-631, 1998. ISSN 00117315.

TVERSKY, A.; KAHNEMAN, D. Judgment under Uncertainty: Heuristics and Biases. Science, v. 185, n. 4157, p. 1124-1131, 1974. ISSN 0036-8075.

VLACHOS, I. P.; BOURLAKIS, M. Supply chain collaboration between retailers and manufacturers: do they trust each other? In: TAYLOR \& FRANCIS. Supply Chain Forum: An International Journal. [S.I.], 2006. v. 7, n. 1, p. 70-80.

WANG, L.; YEUNG, J. H. Y.; ZHANG, M. The impact of trust and contract on innovation performance: The moderating role of environmental uncertainty. International Journal of Production Economics, Elsevier, v. 134, n. 1, p. 114-122, 2011.

WOOLDRIDGE, M. J. Reasoning about rational agents. [S.I.]: MIT press, 2000.

WOTTER, R. G.; TRAVERSI, N. de F.; COSTA, L. T.; DIMURO, G. P.; ADAMATTI, D. F. Natyasastra: A dramatic game for the self-regulation of social exchange processes in mas. In: SPRINGER. International Workshop on Multi-Agent Systems and Agent-Based Simulation. [S.I.], 2017. p. 3-17.

YEUNG, J. H. Y.; SELEN, W.; ZHANG, M.; HUO, B. The effects of trust and coercive power on supplier integration. International Journal of Production Economics, Elsevier, v. 120, n. 1, p. 66-78, 2009. 
ZEE, D.-J. V. D.; VORST, J. G. V. D. A modeling framework for supply chain simulation: Opportunities for improved decision making ${ }^{*}$. Decision Sciences, Wiley Online Library, v. 36, n. 1, p. 65-95, 2005.

ZHANG, M.; HUO, B. The impact of dependence and trust on supply chain integration. International Journal of Physical Distribution \& Logistics Management, Emerald Group Publishing Limited, v. 43, n. 7, p. 544-563, 2013. 